\title{
Influence of tool wear on machining forces and tool deflections during micro milling
}

\author{
Samad Nadimi Bavil Oliaei $^{1} \cdot$ Yiğit Karpat ${ }^{1,2}$
}

Received: 4 June 2015 / Accepted: 24 August 2015 /Published online: 24 September 2015

(C) Springer-Verlag London 2015

\begin{abstract}
Tool wear on the cutting edges of micro end mills is an important issue affecting process outputs such as tool deflections and surface roughness, especially when difficult-tocut materials such as titanium alloys, stainless steel, etc. are machined at micro scale. An understanding of the interactions between tool wear, machining forces, tool deflections, and surface roughness is important in order to maintain component quality requirements. However, in literature, the number of studies concerning tool wear in micro end mills is limited. The goal of the paper is to better understand tool wear patterns (flank wear, edge rounding) of micro end mills and their relationship to machining parameters. In this study, first, the influence of tool wear on micro milling forces and surface roughness parameters is analyzed and favorable micro milling process parameters are identified. It is shown that, when machining with worn end mills, forces are affected by the tool wear patterns. Then, the influence of increased milling forces due to tool wear on tool deflections and tool breakage is studied using both experimental techniques and finite element analysis. The finite element model-based tool deflection and tool breakage predictions are validated through experiments. The results of this study can be used in process parameter selection in pocket micro milling operations and tool condition monitoring systems.
\end{abstract}

Yiğit Karpat

ykarpat@bilkent.edu.tr

1 Department of Mechanical Engineering, Bilkent University, Bilkent, Ankara, Turkey

2 Department of Industrial Engineering, Bilkent University, Bilkent, Ankara, Turkey
Keywords Micro milling · Tool wear · Tool deflections · Surface quality

\section{Introduction}

There is strong demand for the production of micro scale mechanical components to be used in biomedical devices, micro sensors, etc. This ever-increasing demand for micro scale products requires the application of techniques like micro-hot embossing and microinjection molding for the mass production of polymer micro parts with high productivity and repeatability. The tooling systems used in these techniques (micro dies and micro molds) should be specifically oriented to micro fabrication in terms of features, dimensional and geometrical tolerances, and surface quality. A general review of issues in micro/nano manufacturing processes can be found in [1]. While electric discharge machining and micro laser milling can also be used to produce micro molds, they suffer from low material removal rate and surface quality problems. Micro mechanical milling has emerged as a strong alternative since it offers high process flexibility.

Micro mechanical milling is considered the scaled down version of macro scale milling; however, the mechanics of machining at micro scale are quite different. An important difference is the influence of cutting edge radius, which cannot be neglected at micro scale. The edge radius is comparable to the uncut chip thickness during machining, which leads to plowing of the material onto the workpiece surface. It has been shown that there is a minimum uncut chip thickness value where continuous chip formation ceases and plowing becomes the dominant cutting mechanism $[2,3]$. In addition, when grain size is comparable to the uncut chip thickness, it 
Table 1 Experimental conditions for investigating the relationship between radial immersion and feed [18]

\begin{tabular}{lll}
\hline Experiment & Feed $(\mu \mathrm{m} /$ tooth $)$ & Radial immersion $(\%)$ \\
\hline 1 & 2 & 0.2 \\
2 & & 0.6 \\
3 & & 0.8 \\
4 & 4 & 0.2 \\
5 & & 0.6 \\
6 & 6 & 0.8 \\
7 & & 0.2 \\
8 & & 0.6 \\
9 & 0.5 & 0.8 \\
10 & & 0.8 \\
\hline
\end{tabular}

has been shown that the influence of fracture in chip formation increases due to round cutting edge $[4,5]$. The influence of microstructure has also been considered in micro scale machining studies and shown to affect the process outputs significantly $[6,7]$.

Tool run out and tool deflections, which are usually neglected at the macro scale, also gain importance in micro scale machining. The influence of tool runout, which results in varying chip loads on cutting edges of tools, has been integrated into micro milling force models [8]. Tool deflection modeling in micro milling has received considerable attention recently since it affects the quality of the machined micro components [9-12].

Micro end mills with diameters less than a millimeter are usually used in micro milling, and the majority of these tools are made from coated/uncoated tungsten carbide material. During operational conditions, micro tools rapidly wear out and they lose their sharpness, which influences the surface quality [13]. In addition, increased machining forces due to tool wear result in additional deflection of the tools. Tool wear measurement and tool breakage detection are challenging issues in micro milling in terms of achievable dimensional tolerances, surface quality, and economy of the process. Furthermore, the principal wear mechanisms in micro scale cutting do not follow the same patterns, and flank wear measurement is troublesome [14]. Saedon et al. [15] considered micro milling of D2 steel and formulated a tool life equation by using response surface methodology. Their results showed that cutting speed is the most important factor, followed by feed and axial depth of cut. Thepsonti and Özel [16] used a finite elementbased modeling of micro milling and calculated the optimized tool path and milling conditions for micro machining of titanium alloy Ti6AL4V by considering surface roughness and burr formation. They concluded that tool path strongly affects tool wear. Cardoso and Davim [17] studied the effect of micro milling strategies and cutting parameters on surface roughness of Al 2011 aluminum alloy. Based on their findings, a constant overlap spiral milling strategy produced the best surface roughness. In a recent study, Oliaei and Karpat [18] considered circular pocket micro milling of Stavax stainless steel and also observed that radial depth of cut and feed per tooth must be selected carefully in order to maximize productivity in pocket micro milling. They observed a high wear rate at low feed and radial immersion milling cases. Liu et al. [19] found that low feed improves the surface quality in micro milling titanium alloy and emphasized the importance of tool run out on the process. Jun et al. [20] investigated the influence of feed rate on tool wear. They observed that each tooth experiences a different amount of wear during machining. They proposed a tool wear term defining the average increase in cutting edge radius.

There is a limited number of studies in the literature concerning the influence of tool wear on tool deflections and surface roughness in micro milling. This study aims to advance the understanding of the interactions between process inputs and outputs by applying experimental and modeling techniques. The evolution of tool wear in micro end mills under different machining conditions is investigated. The influence of tool wear on
Fig. 1 a Spiral tool path for the circular pocket and $\mathbf{b}$ micro milled circular pockets

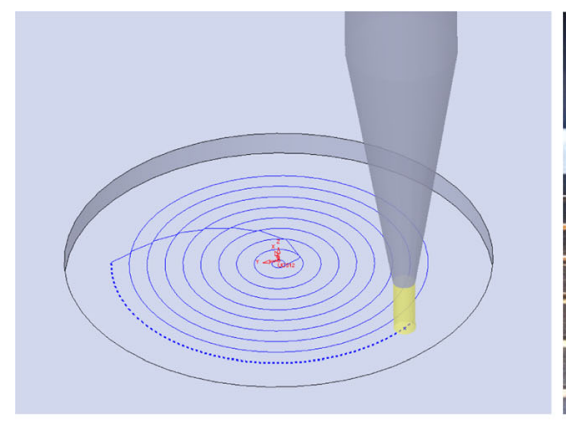

(a)

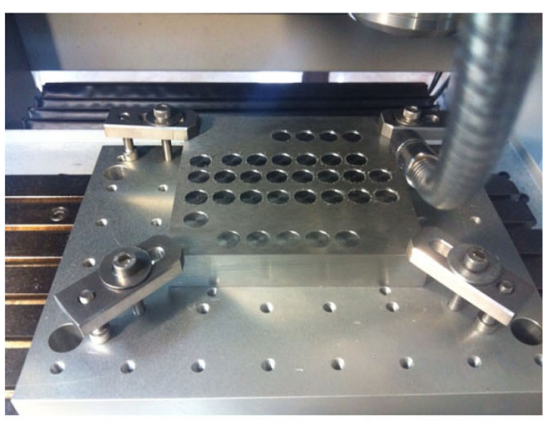

(b) 
process outputs is studied using experimental and computational techniques. The selected work material is Stavax stainless steel, a common material used in the mold making industry due to its improved machinability.

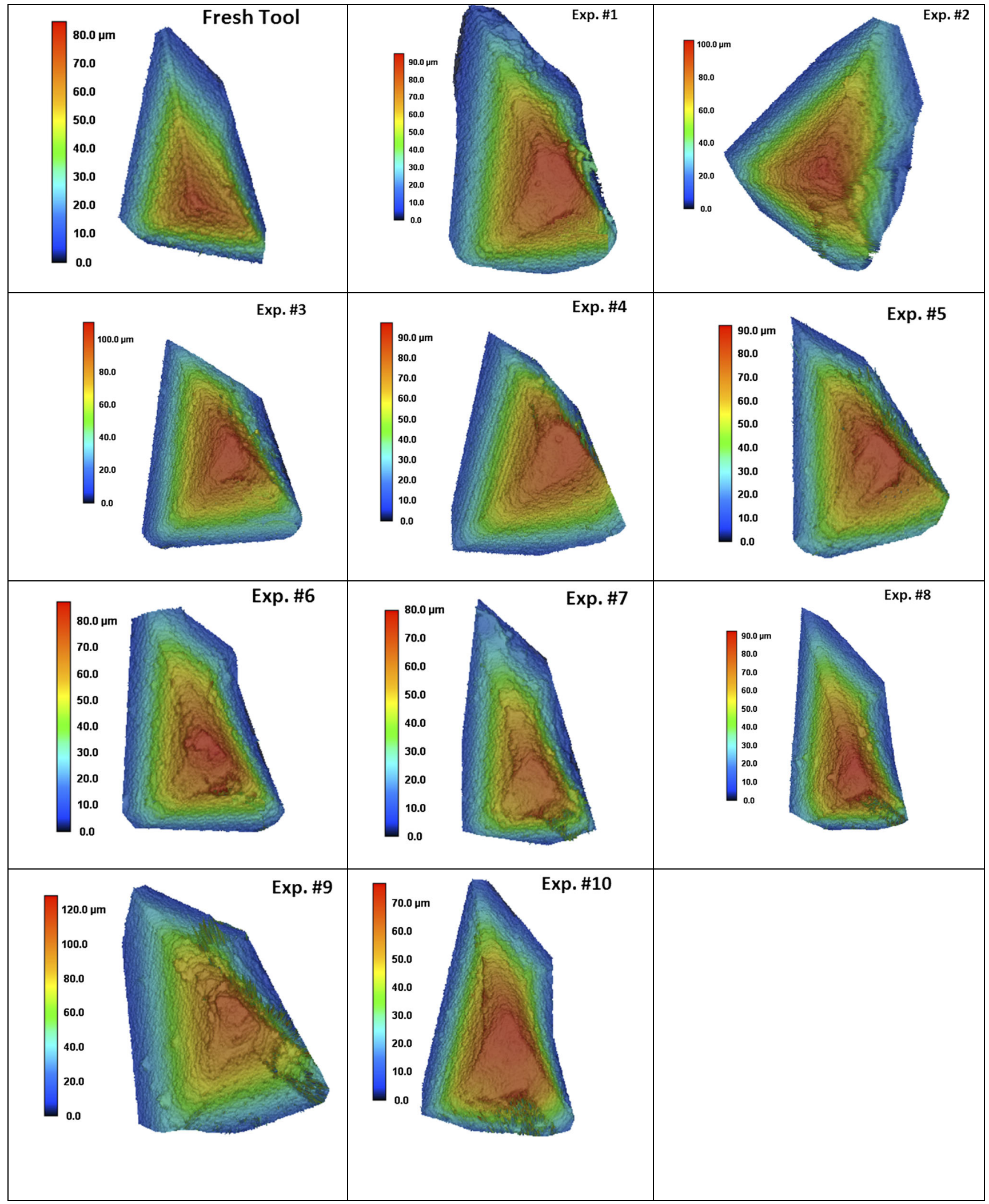

Fig. 2 Laser topography images of worn cutting edges 


\section{Overview of milling parameters on wear of micro end mills}

Our previous investigation [18] was conducted to understand the relationship between milling process parameters (radial immersion and feed per tooth) and tool wear during circular pocket micro milling of Stavax with tungsten carbide micro end mills. The purpose of using circular pocket milling was to observe the influence of radial immersion percentage during spiral milling and to extend the machining time without interrupting the process. The relationship between radial immersion and feed per tooth is important to maintain a balance between tool life and productivity during pocketing operations. In the micro milling experiments, cutting speed $(38 \mathrm{~m} / \mathrm{min})$ and axial depth of cut $(160 \mu \mathrm{m})$ were kept constant. Square end micro end mills with $0.8 \mathrm{~mm}$ in nominal diameter were employed in the experiments (NS tools MSE 230, $\varnothing 0.8 \times 2,2$ teeth, $30^{\circ}$ helix angle). The work material was selected as Stavax (modified AISI 420 stainless steel), a widely used material in the mold-making industry. Table 1 shows the list of experimental conditions used. Three levels for feed per tooth are selected as 2,4 , and $6 \mu \mathrm{m} /$ tooth, and three levels of radial immersion are selected as 20,60 , and $80 \%$ of the tool diameter. For comparison, an additional experiment is also conducted at a very low feed rate of $0.5 \mu \mathrm{m} /$ tooth. In order to decrease the influence of plunging during entry to material, predrilled holes were used for each circular pocket. A total of six pockets with
$15 \mathrm{~mm}$ in diameter were machined for ten different experimental conditions. Figure 1 shows the spiral tool path and micro milled circular pockets.

\section{Investigation of tool wear in micro end mills}

Measuring tool wear in micro end mills is challenging because of the small sizes of the tools. A reliable criterion about the condition of the cutting edge of the micro tools has not been set yet. Figure 2 shows the worn edges of the micro end mills obtained through a laser topography microscope (Keyence VKX 100) as a result of circular pocket milling under the conditions shown in Table 1. The images show a considerable amount of edge rounding and flank wear on the cutting edges. Built up edge on the cutting edges was not observed. In this study, a similar approach as Jun et al. [20] has been used where the effective diameter of the tool is measured. The edge rounding increases during machining and results in a decrease in effective tool diameter. It must be noted that the diameters of the micro end mills are usually lower than their nominal diameter of $800 \mu \mathrm{m}$. It is also known that tool diameters of end mills are not equal even when tool samples are taken from the same batch. For all the experimental conditions given in Table 1, the diameter of the micro tools at the beginning of the experiment was recorded, and average effective diameter of end mills has been measured at the end of each pocket milling operation.

Fig. 3 Optical images of tool profiles: a upsharp tool and $\mathbf{b}$ worn tool
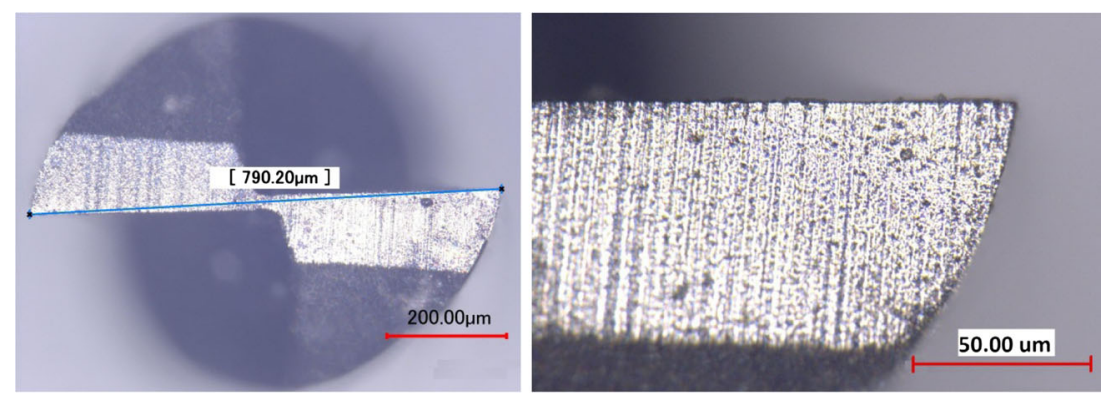

(a)
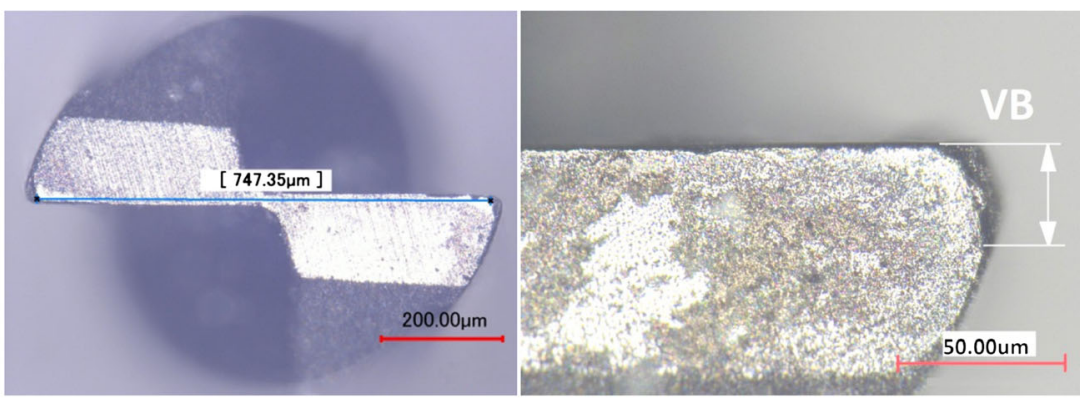

(b) 
Figure $3 \mathrm{a}, \mathrm{b}$ shows the comparison of upsharp and worn tools (images are taken with Keyence VHX-1000 digital microscope). When the worn edges are investigated, a flank wear zone (VB) and edge rounding can be clearly seen. The diameter reduction due to edge rounding is shown in Fig. 3b. The results of diameter reduction and flank wear length measurements for each experimental case are shown in Fig. 4a, b with respect to number of pockets milled. In order to eliminate the influence of initial tool diameter on the diameter reduction values, the measurements are normalized relative to upsharp tool diameter values for each tool. Equation 1 has been applied to obtain the ranked results as shown in Fig. 5a. Figure 5b shows the flank wear length measurements.

Relative ToolDiameter Reduction $\%=\frac{D_{\mathrm{up}}-D_{\mathrm{worn}}}{D_{\mathrm{up}}} \times 100$ (1)

Diameter reduction percentage and average flank wear length can be considered as two different measures of tool wear. According to the results given in Fig. 5a, experimental condition $\# 5$, which is the medium level combination of feed and radial immersion, seems to be a favorable machining case in terms of relative diameter reduction criteria. Yet, it must be noted that the difference with other milling
Fig. 4 a Average effective diameters at the end of each pocket milling and $\mathbf{b}$ variation of average flank wear length as a function of pocket number

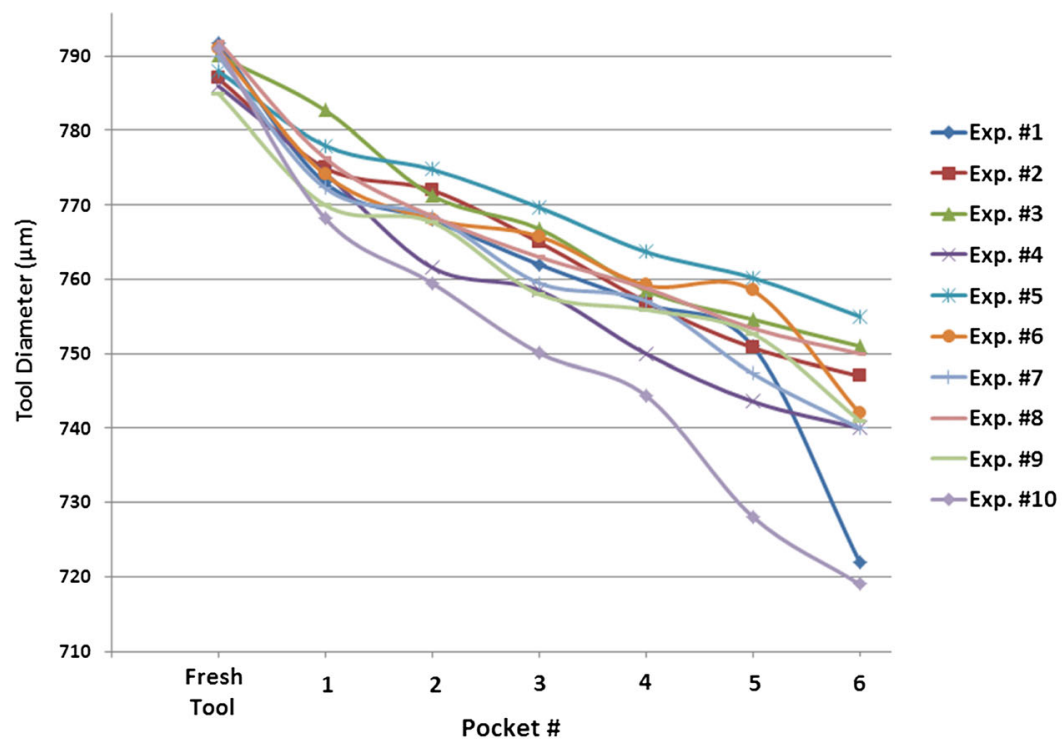

(a)

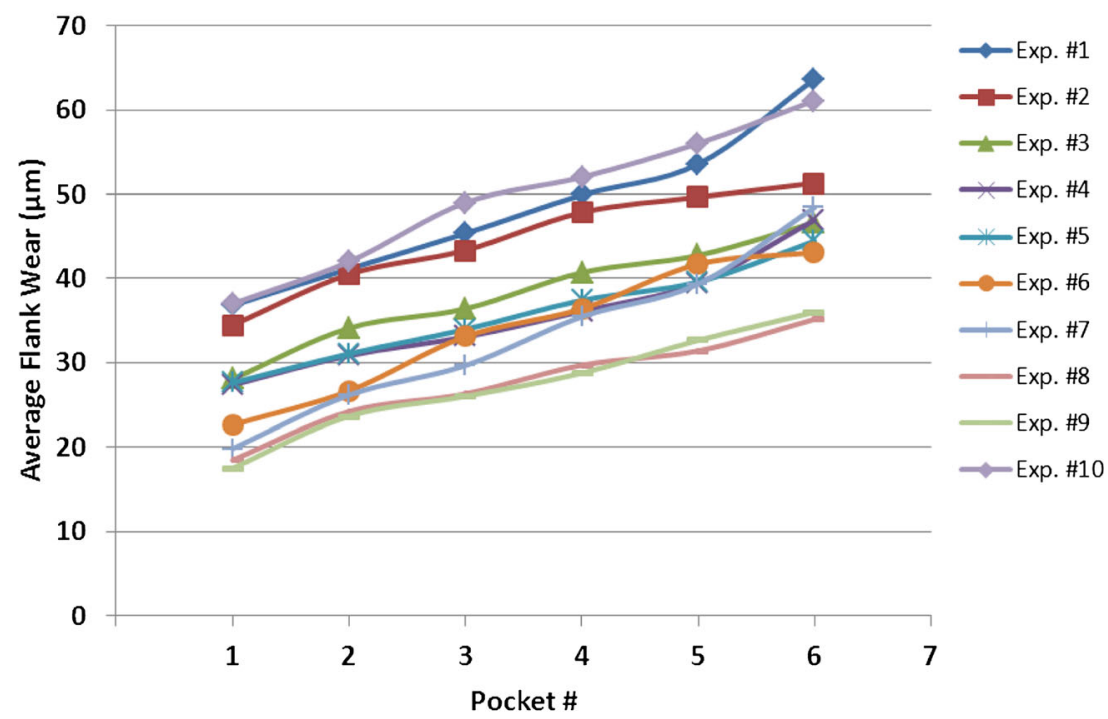

(b) 


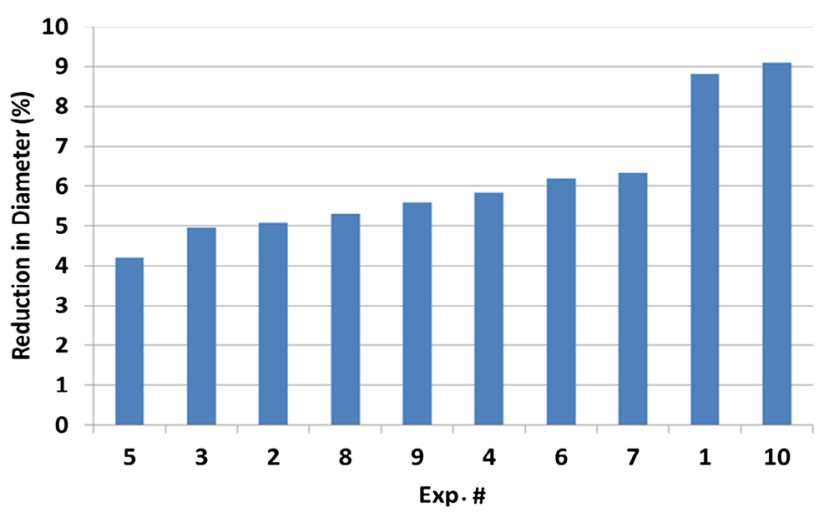

(a)

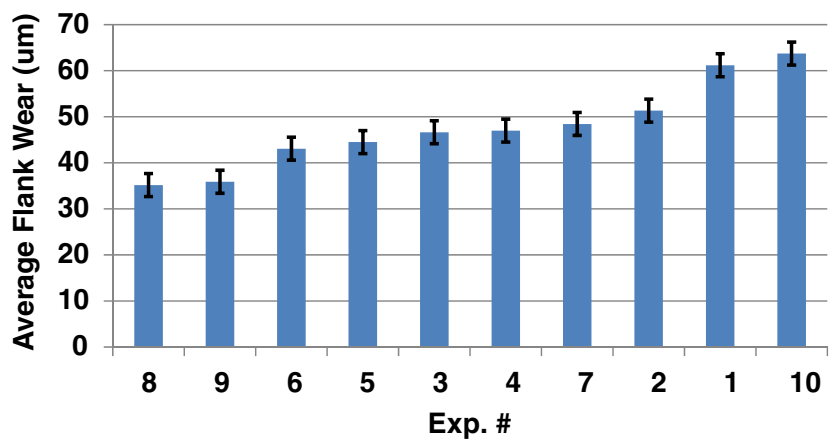

(b)

Fig. 5 a Relative tool diameter reduction criterion and $\mathbf{b}$ comparison of flank wear length after machining tests

cases (experimental conditions \#2 and \#3) is quite small. Figure $5 \mathrm{~b}$ compares flank wear length at the end of the micro milling experiments. For flank wear values, however, experiments \#8 and \#9 yielded more favorable results compared to other cases. The measurement of wear volume combines both flank wear and edge rounding effects on a single measurement indicating the total loss of material from the cutting tool edge. Wear volume is computed for each experimental case by considering the laser topography images of the cutting edges given in Fig. 2. Figure 6 illustrates the ranking of measured wear

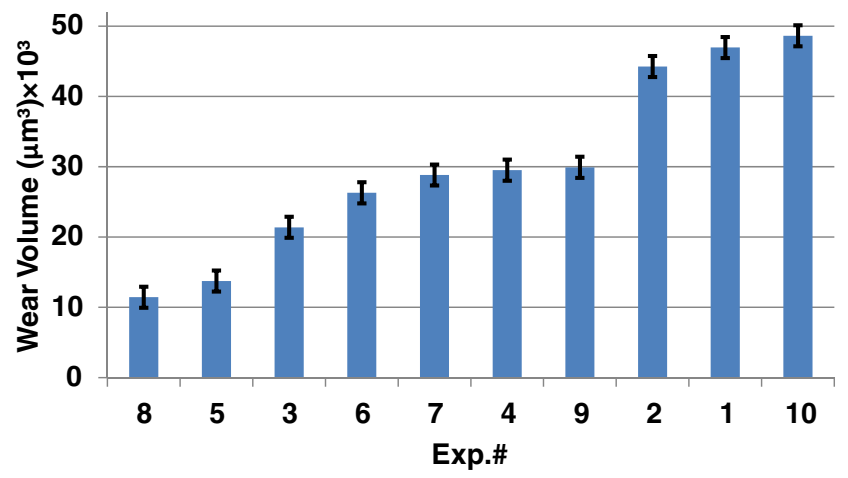

Fig. 6 Wear volume comparison volumes for each cutting edge. Based on the wear volume results, it can be understood that low radial immersion leads to higher wear volume. When low radial immersion is used, increasing feed rate improves the tool life. For high radial immersion (80\%), decreasing feed up to a certain level can also improve tool life, but for very small feed rates, tool life decreases drastically as is the case of experiment \#10. Low feed milling cases yielded more flank wear and lower edge rounding on the tool.

\section{Influence of tool wear on micro milling forces and surface roughness}

A new set of experiments has been conducted on worn tools, and the influence of tool wear on surface roughness and milling forces is investigated. Slot milling experiments were conducted at various feed rates, and forces and surface roughness were measured for each worn tool. Based on mechanistic modeling approach, cutting and edge force coefficients are calculated with the assumption that the influence of tool wear is reflected on the force coefficients. The experimental setup is explained in the next section.

\subsection{Experimental setup for slot milling tests with worn tools}

In the new set of experiments, cutting speed and axial depth of cut are kept the same as previous tests. Four different feed per tooth values $(4,6,8$, and $10 \mu \mathrm{m} /$ tooth) were considered as shown in Table 2. Micro machining forces are measured by Kistler mini dynamometer $(9256 \mathrm{C} 1)$ with its charge amplifier (type 5080A) and transferred to a PC through a data acquisition card (National Instruments). A high-speed spindle NSK HES 510 was attached to the spindle of DMG HSC 55 milling machine. All experiments are performed under dry machining conditions. The tool runout is measured to be around $1 \mu \mathrm{m}$. Figure 7 shows the experimental setup.

\subsection{Influence of tool wear on surface roughness}

Surface roughness is an important process output in terms of part quality, yet it is the most difficult to analyze, especially at the micro scale machining. Milling parameters, tool offset, and machining vibrations also significantly affect the surface

Table 2 Experimental conditions for machining tests with worn tools

\begin{tabular}{llc}
\hline Tool & Feed per tooth & Depth of cut \\
\hline $\begin{array}{l}\text { Worn tools used in } \\
\text { experiments 1 to } 10\end{array}$ & $4,6,8$, and $10 \mu \mathrm{m} /$ tooth & $160 \mu \mathrm{m}$ \\
\hline
\end{tabular}




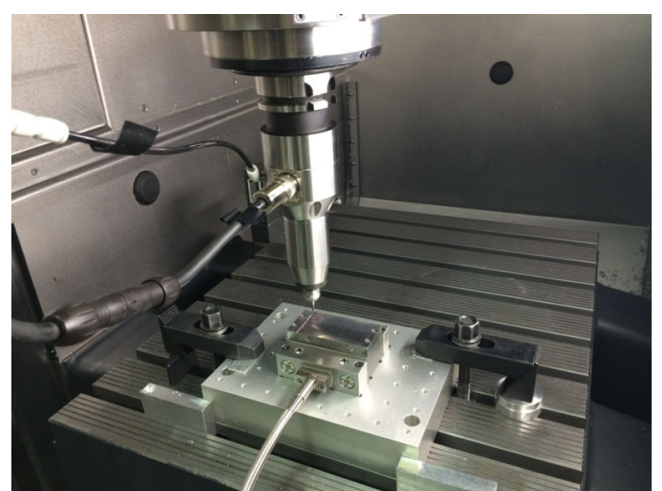

Fig. 7 Experimental setup for milling tests

topography $[21,22]$. In this study, a non-contact method of surface roughness measurement was used to analyze the influence of tool wear on machined surfaces. A 3D laser scanning microscope (Keyence VK-X100) with a resolution of $5 \mathrm{~nm}$ and a repeatability of $0.02 \mu \mathrm{m}$ is used for contactless surface roughness measurements. The microscope allows measurement of both line roughness (e.g., $\left.R_{\mathrm{a}}\right)$ and areal topography surface roughness (e.g., $S_{\mathrm{a}}$ ) (ISO 25178) [23]. In this study, arithmetic mean height $\left(R_{\mathrm{a}}\right)$ and average distance between the highest peak and lowest valley $\left(R_{\mathrm{z}}\right)$ values are considered to characterize surface roughness parameters. In measurements, the highest magnification is used which yields a small measurement area of $135 \mu \mathrm{m} \times 101 \mu \mathrm{m}$. Image stitching capability of the laser microscope is used to form a larger area which can be used for surface characterization. Noise filtering and planar tilt correction are applied to a region of interest with a size of $750 \mu \mathrm{m} \times 750 \mu \mathrm{m}$ before extracting $R_{\mathrm{a}}$ and $R_{\mathrm{z}}$ values. A cut-off $\left(\lambda_{\mathrm{c}}\right)$ value of $80 \mu \mathrm{m}$ was used to remove the influence of waviness from surface roughness measurements. Figure 8 illustrates the images obtained for different channels machined under the same machining conditions with worn micro tools (at $f=8 \mu \mathrm{m} /$ tooth).

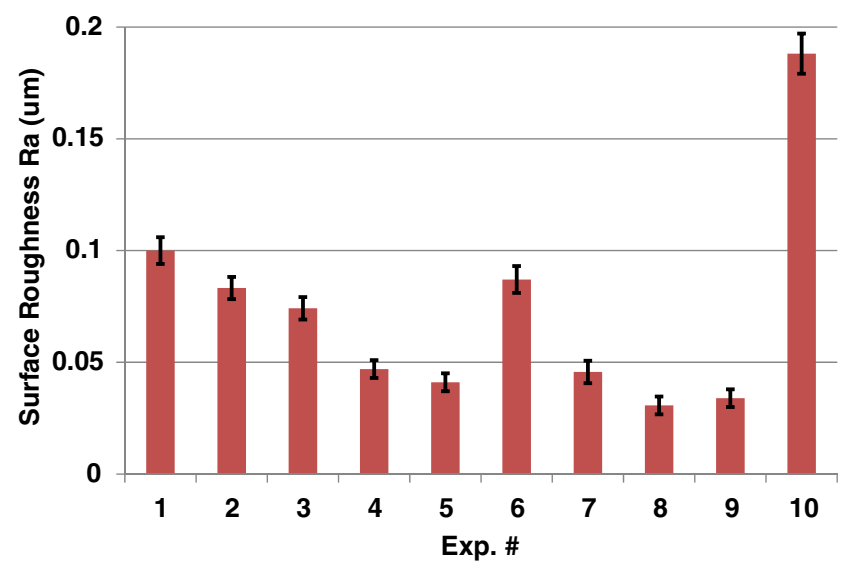

(a)

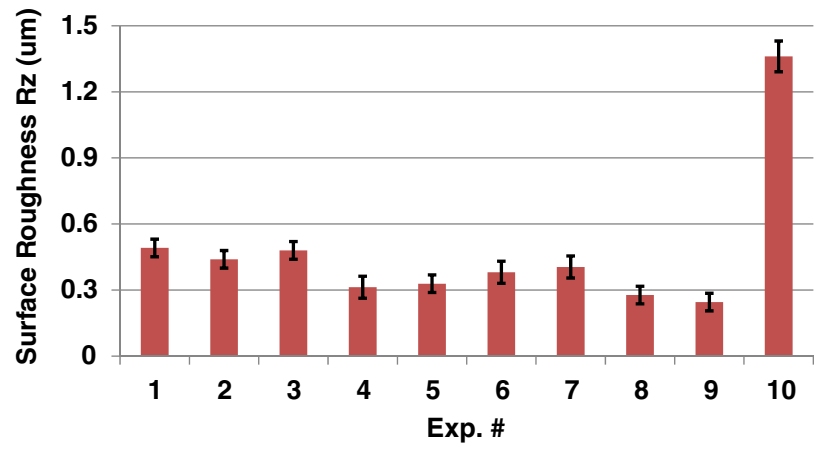

(b)

Fig. 9 Surface roughness of the machined channels: $\mathbf{a} R_{\mathrm{a}}$ value and $\mathbf{b}$ $R_{\mathrm{z}}$ value

Figure 9a, b shows the $R_{\mathrm{a}}$ values and the $R_{\mathrm{z}}$ values, respectively. The worn tools used at experiments \#5 and \#8 yielded lower $R_{\mathrm{a}}$ values. These results are in good agreements with wear volume comparison. However, worn tool used at experiment \#3 exhibited higher $R_{\mathrm{a}}$ value compared to tools used in experiments \#5 and

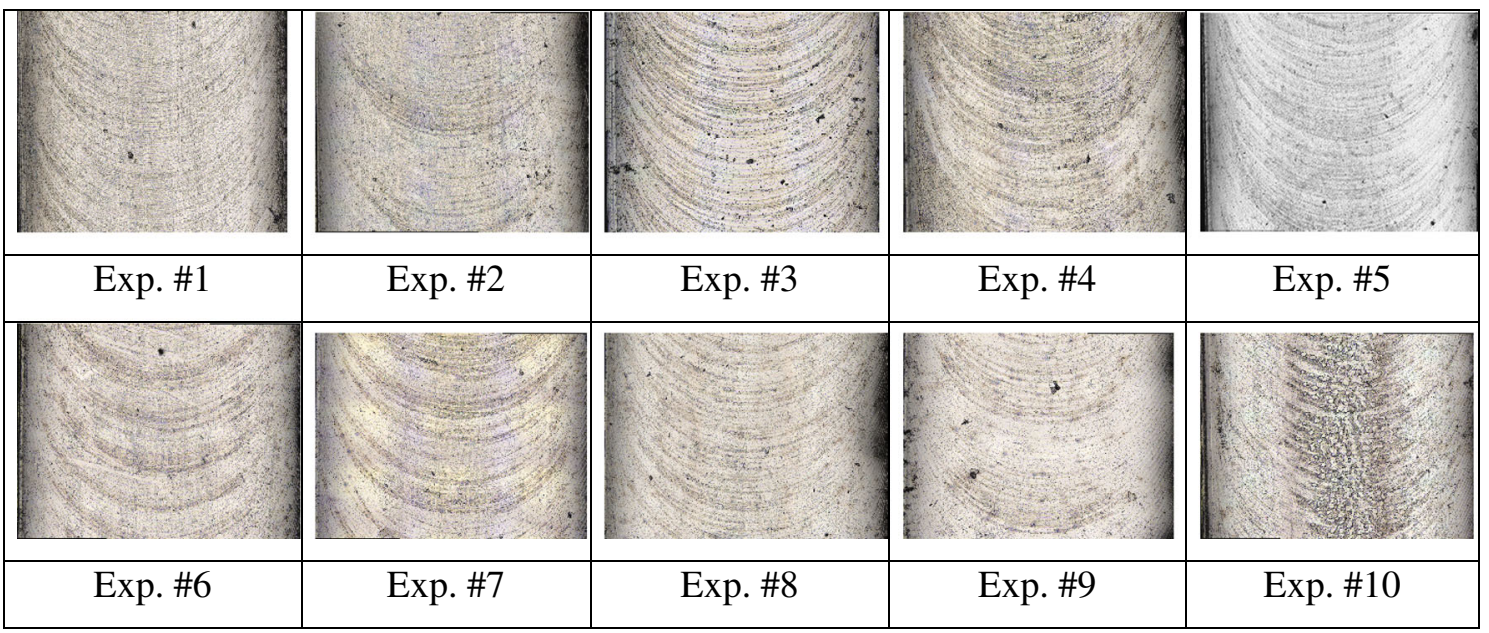

Fig. 8 Surface of the channels produced with different worn tools 
\#8. The worn tool used in experiment \#10 presented the worst results in terms of surface roughness. The differences in surface roughness $\left(R_{\mathrm{z}}\right)$ between experiments $\# 9$, \#10, and \#6 are quite striking since both have the same radial immersion but different feed per tooth values. This result clearly shows the importance of selecting compatible radial immersion and feed values during process planning stage. It must be noted that surface roughness is of particular concern during the finishing process, where upsharp tools are usually utilized. However, selecting low feed and low radial immersion for better surface finish also leads to rapid tool wear, especially when machining difficult-to-cut materials.

\subsection{Investigation of micro milling force measurements with worn tools}

Figure 10 illustrates the cutting forces $\left(F_{x}, F_{y}\right)$ obtained for each tool at a feed rate of $4 \mu \mathrm{m} /$ tooth. Each slot milling experiment was repeated for all feed values and average forces in $x$ (parallel to direction of cut) and $y$ (perpendicular to cutting direction) directions are calculated. Figure 11 illustrates the average of $F_{x}$ and $F_{y}$ forces as a function of feed in slot milling experiments. Figures 10 and 11 also show the cutting forces obtained for upsharp tool.

In milling force modeling, cutting forces in $x$ and $y$ directions can be calculated by using Eq. 2 where $a_{\mathrm{p}}$ represents the depth of cut, and the tool rotation angle is represented with the angle $\phi$. Tangential $\left(F_{\mathrm{t}}\right)$ and radial $\left(F_{\mathrm{r}}\right)$ forces acting on the tool are utilized to calculate the milling forces with respect to a fixed reference system. Milling forces are dependent on the number of teeth on the cutter $(z)$ and the radial immersion $\left(a_{\mathrm{e}}\right)$. Whether a given tooth is in contact with the material or not is controlled through the parameter $g$.

$\left[\begin{array}{l}F_{x}(\varnothing) \\ F_{y}(\varnothing)\end{array}\right]=a_{\mathrm{p}} \sum_{j=0}^{z^{-1}} g_{j}\left(\left[\begin{array}{cc}\cos \varnothing & \sin \varnothing \\ \sin \varnothing & -\cos \varnothing\end{array}\right]\left[\begin{array}{c}F_{\mathrm{t}}(\varnothing) \\ F_{\mathrm{r}}(\varnothing)\end{array}\right]\right)(2$

Mechanistic modeling techniques have been used to relate the tangential and radial forces to uncut chip thickness $(h)$ through cutting and edge force coefficients $[24,25]$. In Eq. $3, K_{\text {tc }}, K_{\text {te }}, K_{\text {rc }}$, and $K_{\text {re }}$ represent the unknown cutting and edge force coefficients which must

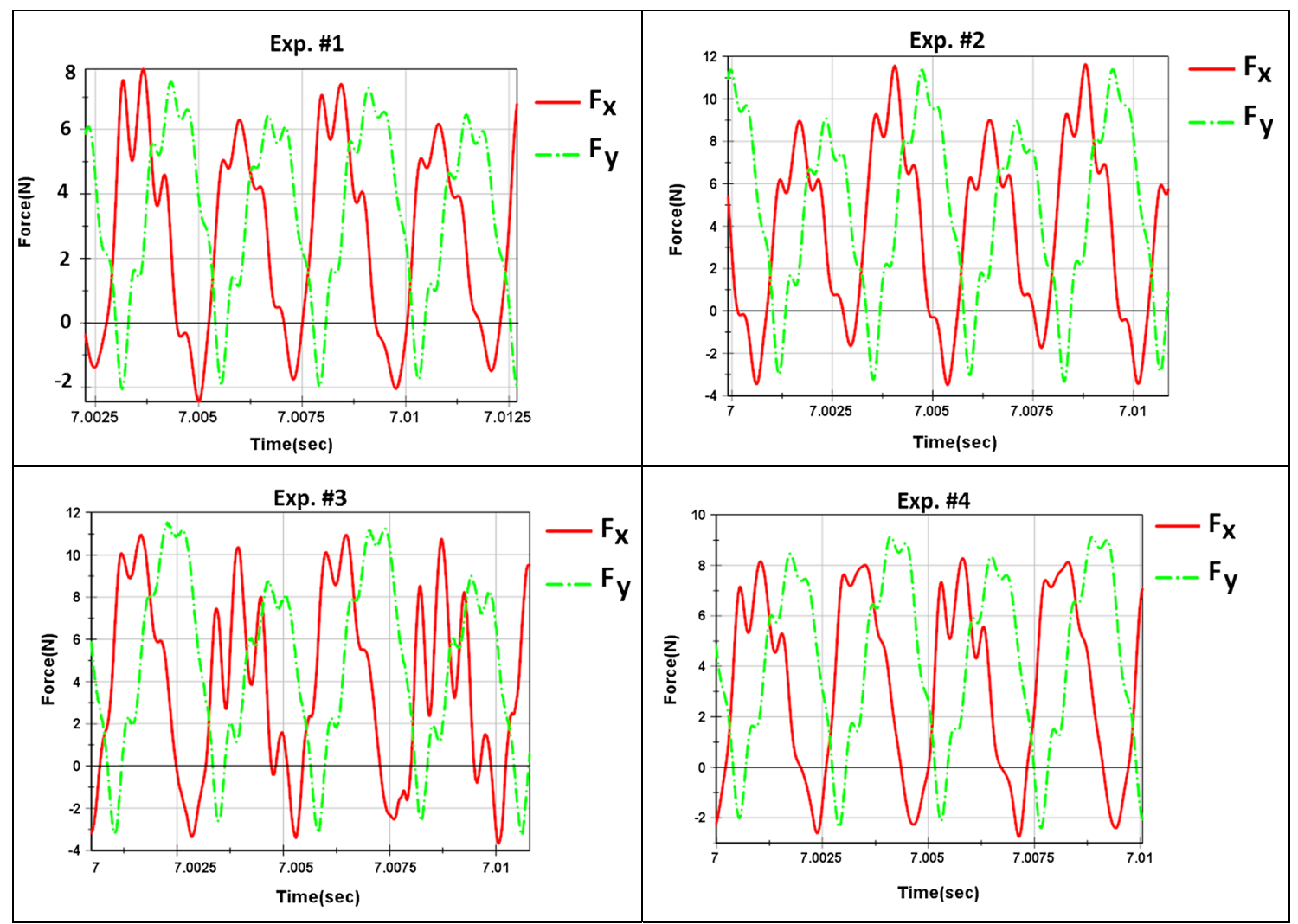

Fig. 10 Force signals obtained during slot milling experiments 


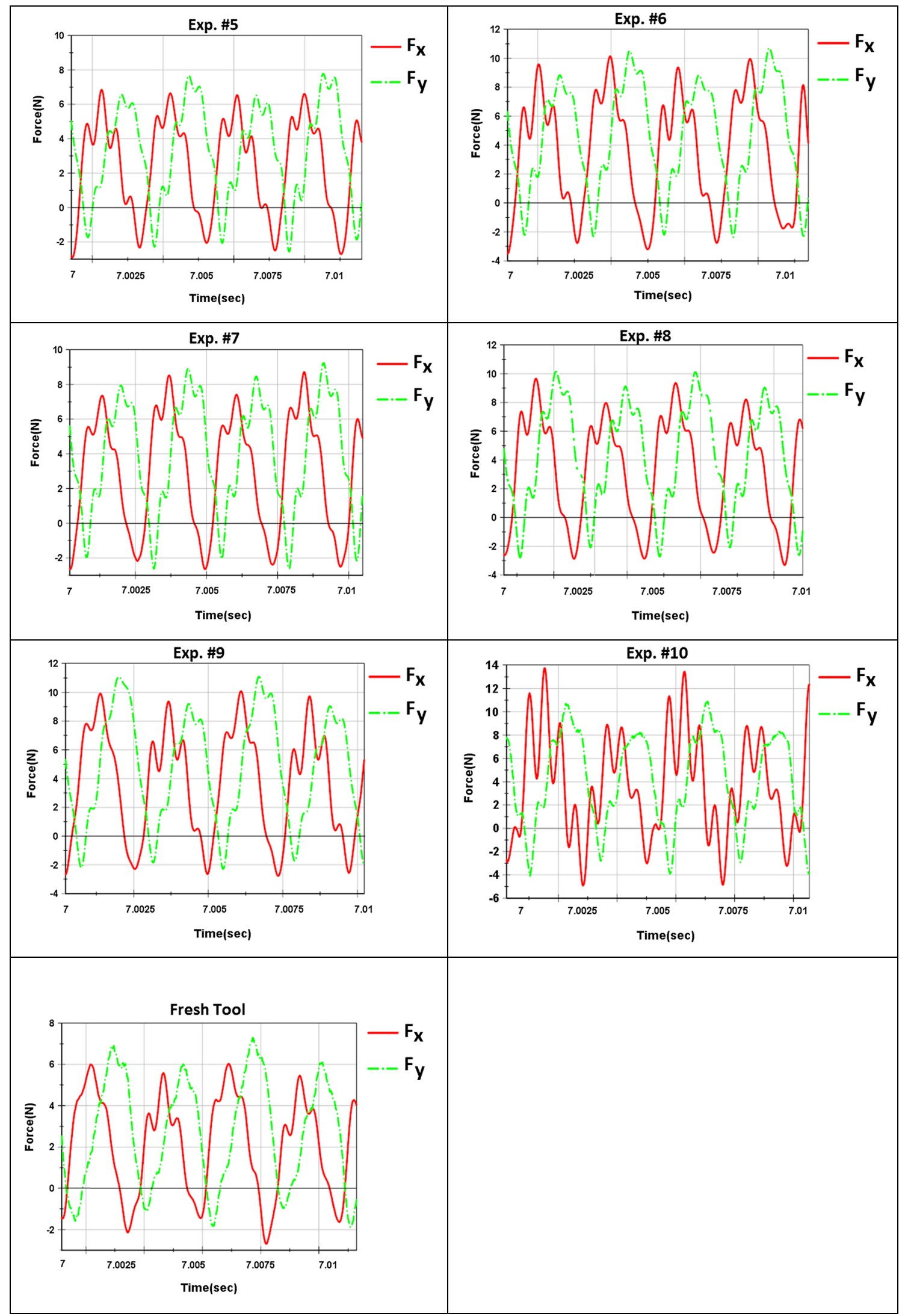

Fig. 10 (continued) 


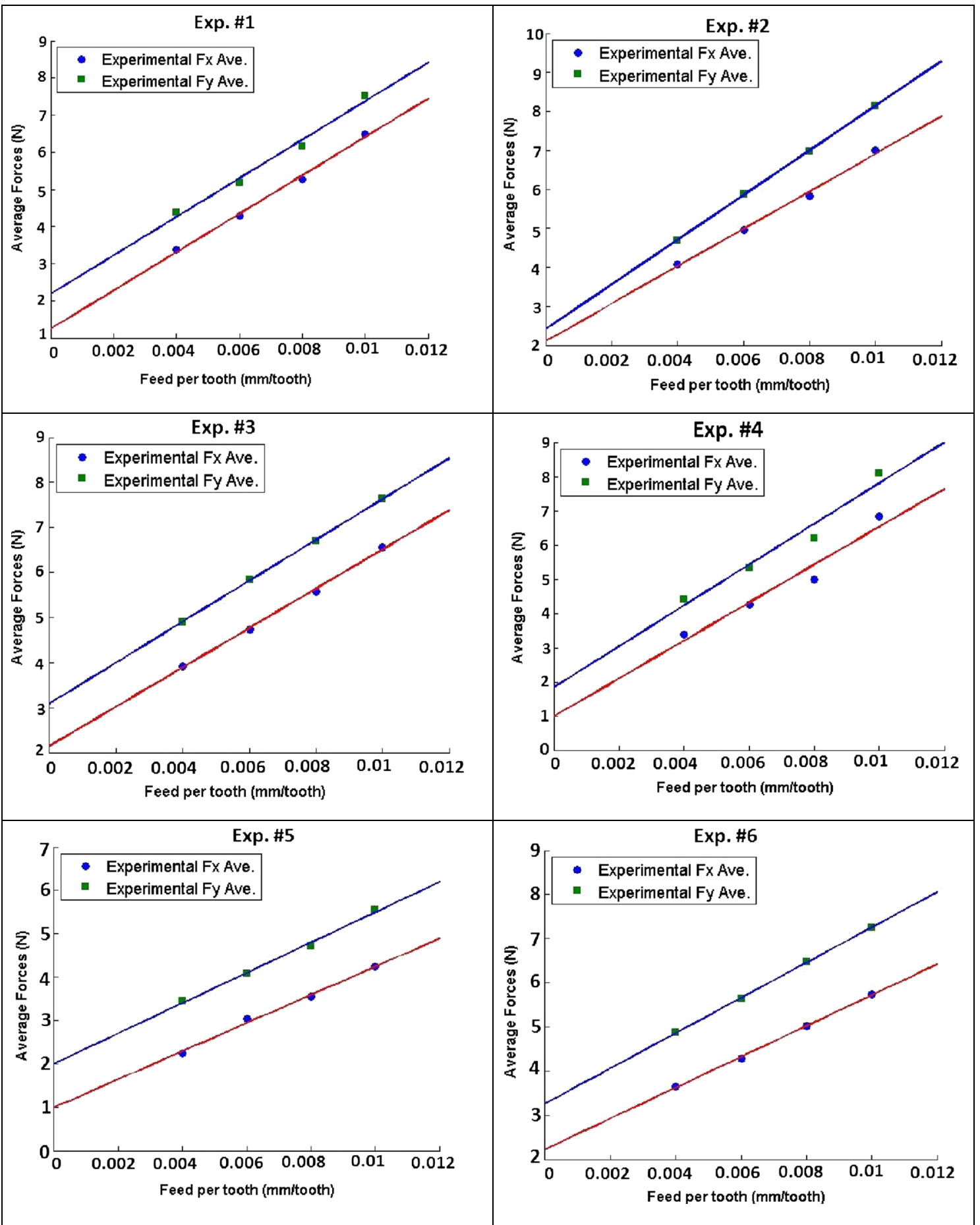

Fig. 11 Average cutting forces in $x$ and $y$ directions as a function of feed

be calculated for a given combination of tool geometry and workpiece material.

$$
F_{\mathrm{t}}(\phi)=K_{\mathrm{tc}} h(\phi)+K_{\mathrm{te}}
$$$$
F_{\mathrm{r}}(\phi)=K_{\mathrm{rc}} h(\phi)+K_{\mathrm{re}}
$$

As mentioned earlier, tool runout is also an important consideration in micro milling and it has been integrated into milling models by considering the varying chip thickness depending on the location of tool runout. The runout model proposed by $\mathrm{Li}$ et al. [8] has been used in this study. Using Eqs. 2 and 3, unknown cutting 


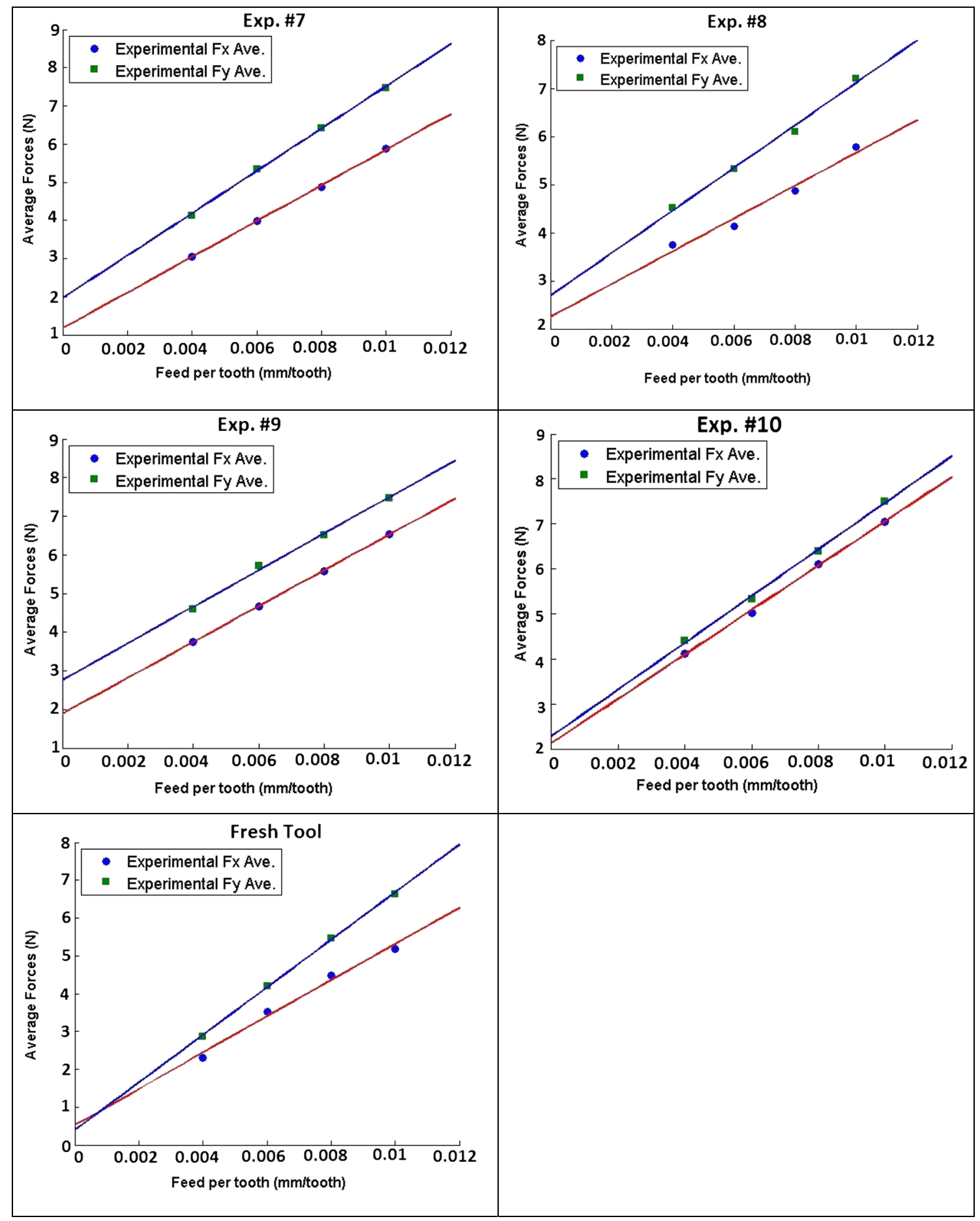

Fig. 11 (continued)

and edge force coefficients can be calculated by utilizing slope and intercept values shown in Fig. 11. Figure 12a shows the comparison of the calculated cutting force coefficients $\left(K_{\text {tc }}\right.$ and $K_{\text {rc }}$ ), and Fig. 12b shows the comparison of edge force coefficients $\left(K_{\mathrm{te}}\right.$ and $\left.K_{\mathrm{re}}\right)$ for each worn tool.
As expected, the upsharp micro end mill yielded the lowest edge force coefficients and high cutting force coefficients. For worn tools, edge force coefficients in the tangential direction are larger than in the radial direction, which would imply that edge rounding is more severe than flank wear. Figure 13 shows the cross-sectional area of the micro end mill (used in 


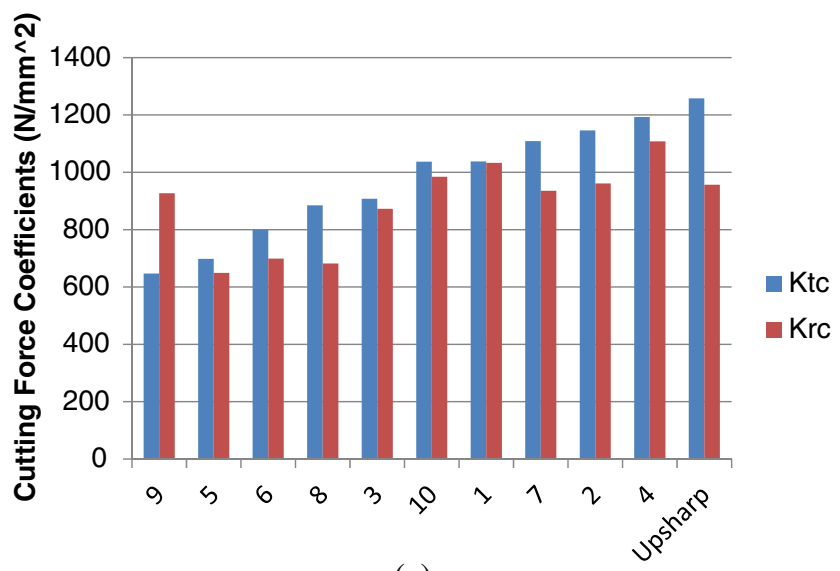

(a)

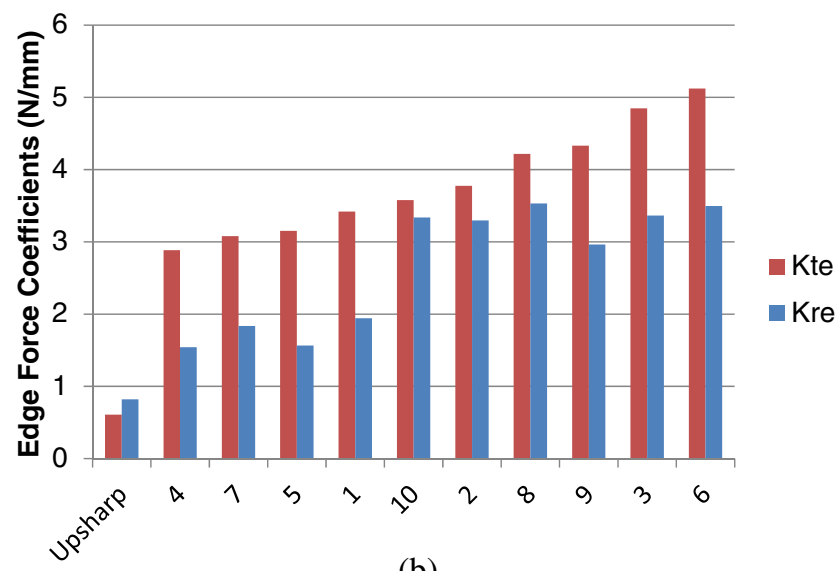

(b)

Fig. 12 Comparison of a cutting force coefficients and $\mathbf{b}$ edge force coefficients

experiment \#2) obtained after sectioning it with micro wire electro discharge machining. There is a considerable increase in the cutting edge radius from the initial $\sim 2-3 \mu \mathrm{m}$ to $\sim 20 \mu \mathrm{m}$ on one edge and to $\sim 12 \mu \mathrm{m}$ on the other.

Interestingly, the worn tool used in experiment $\# 5$ which exhibited low wear volume and produced the lowest $R_{\mathrm{a}}$ and $R_{\mathrm{z}}$ values also has the lowest $K_{\text {re }}$ value along with worn tools used in experiments \#4 and \#7. However, $K_{\mathrm{tc}}$ and $K_{\mathrm{te}}$ values of the worn tool used in experiment $\# 5$ are also lower. This result implies that a large edge rounding has occurred and increasing feed per tooth does not increase the average forces significantly, probably due to the feed values less than the edge radius of the tool. As for the worn tool used in experiment $\# 4$, edge force coefficients are low and cutting force coefficients are large, similar to upsharp tool, whereas its wear volume measurements were high. It implies that edge sharpening due to flank wear yields larger cutting force variation with increasing feed values although the wear volume is larger. Figure 14 shows the sections of the cutting edges that explain the situation observed here. The analysis of cutting forces and surface roughness in conjunction with wear measurements reveals that the tool used under the conditions of experiment \#5 $(f=4 \mu \mathrm{m} /$ tooth and radial immersion of $60 \%)$ experiences lower cutting forces and produces better surface quality. This result agrees well with the diameter reduction-based analysis of tool wear as shown in Fig. 5a.

In general, tool wear during micro milling of circular pockets is observed to evolve as edge radius and flank wear increase, as illustrated in Fig. 15. Based on our findings, edge rounding and flank wear development follow a certain pattern depending on the selection of feed and radial immersion parameters. Tool wear evolution is important, since it affects the directions of radial and tangential forces acting on the cutting edge. In order to continue machining effectively with worn tools, one possible strategy would be to increase feed per tooth as cutting edge radius increases. However, this increase is limited by the tool deflection and tool breakage, which is investigated in the next section.

\section{Tool deflection modeling with finite element analysis}

As tool wear progresses, milling forces increase, and as a result of increasing machining forces, micro end mills considerably deflect and finally reach to the point of fracture. The limits of tool fracture are important especially for process planning, tool condition monitoring, and tool design purposes. Using an experimental approach, Uriarte et al. obtained the stiffness chain of the micro milling machine by considering the stiffness levels of the machine tool, spindle, tool holder,

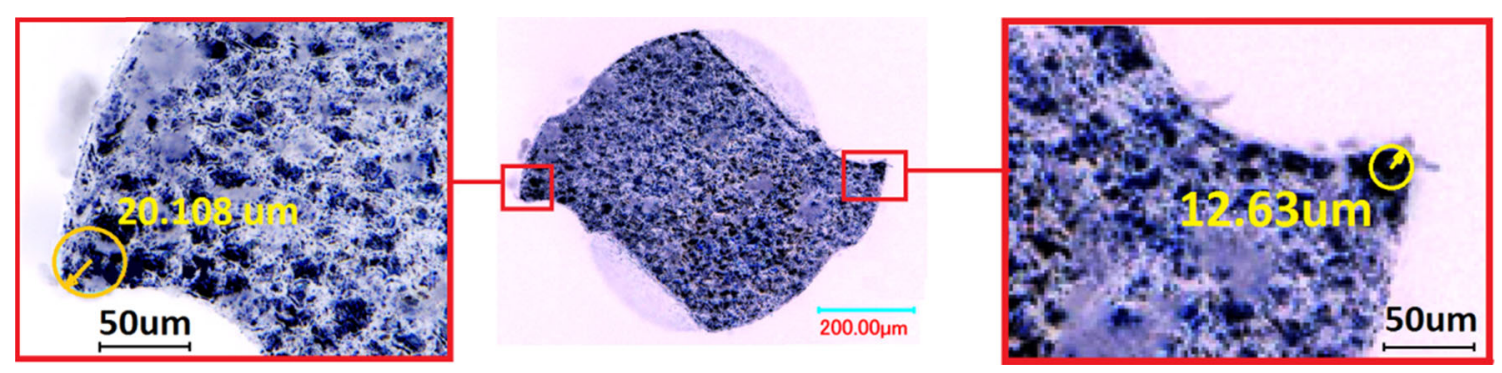

Fig. 13 Cross-sectional area of micro end mill and edge radius (experiment \#2) 


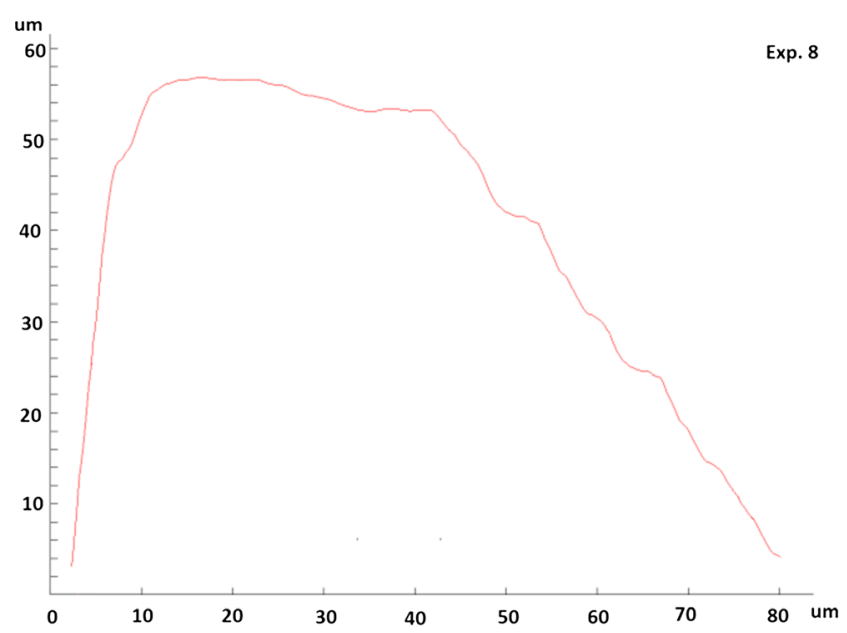

(a)

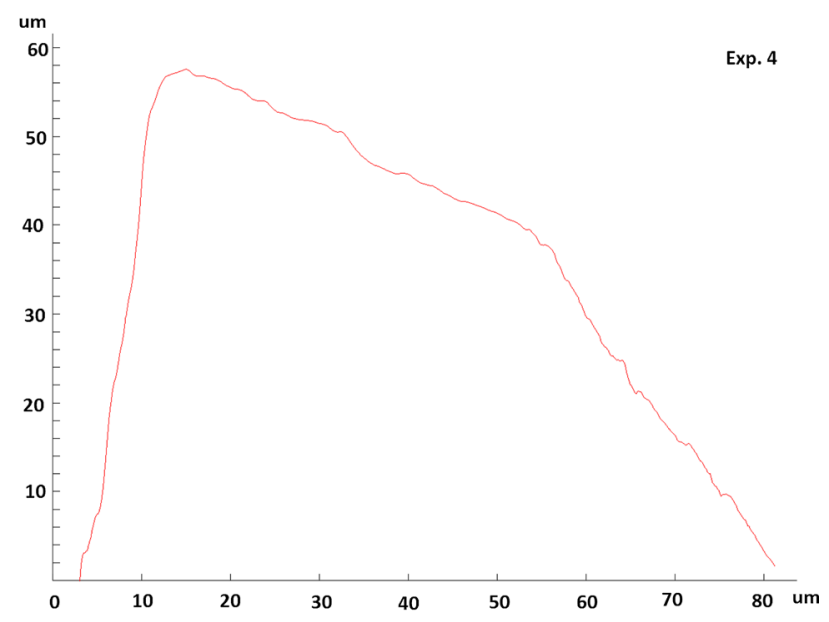

(b)

Fig. 14 Two different cases of edge wear identified from experiments: a worn tool used in experiment \#8 and b worn tool used in experiment \#4

and the tool itself [9]. Based on their assessment, for micro milling, the compliance of the tool accounts for up to 80-90\% of the total compliance of the system. Therefore, unlike
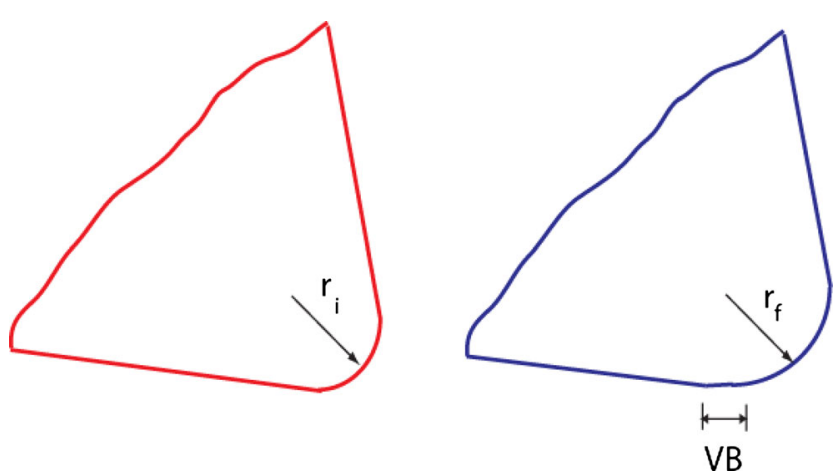

Fig. 15 Two different wear mechanism identified from experiments (initial edge radius $\left(r_{\mathrm{i}}\right)$ is smaller than final edge radius $\left(r_{\mathrm{f}}\right)$ )

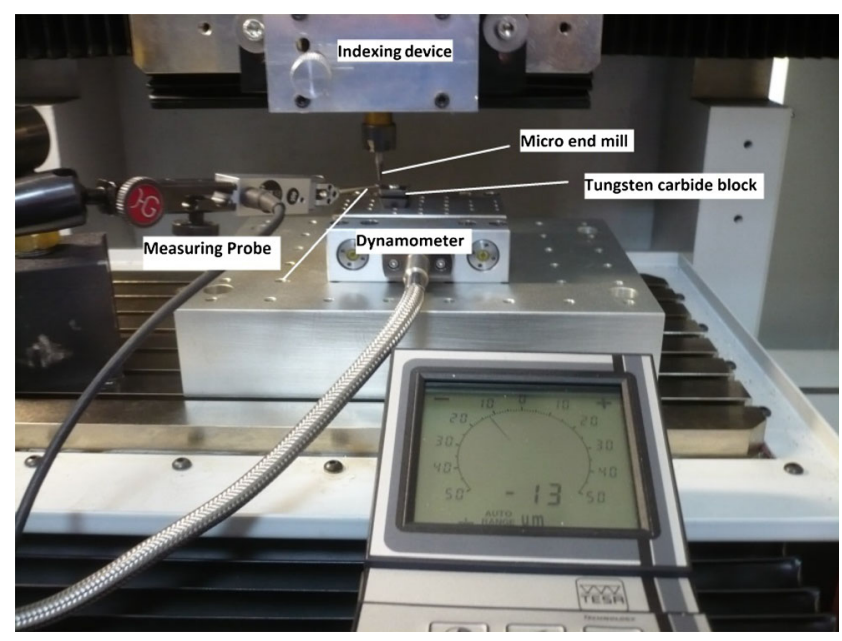

Fig. 16 Experimental setup used for tool deflection measurements

conventional milling [26], micro tools are the main source of compliance in the micro milling stiffness chain. In this section, the influence of worn milling forces on tool deflection is studied by using finite element modeling. An experimental setup has been prepared to measure the tool deflection under the action of static forces as depicted in Fig. 16. The cutting tool is mounted on an indexing device attached to the $Z$ axis of the machining center with the same overhang used in micro milling experiments. The use of an indexing device makes it possible to lock the tool to avoid its rotation and to apply the force at different angles. To measure the tool deflection, a TESA GT31 lever probe with a repeatability of $0.1 \mu \mathrm{m}$ is used. The probe is attached to a Tesatronic TT10 display unit. The static force is applied by pushing the tool against a rigid tungsten carbide block mounted on Kistler mini dynamometer.

The tool is programmed to move $0.5 \mu \mathrm{m}$ towards the tungsten block at a low feed rate of $0.5 \mathrm{~mm} / \mathrm{min}$. Figure 17 illustrates the time history of the applied forces on the tip of the micro end mill.

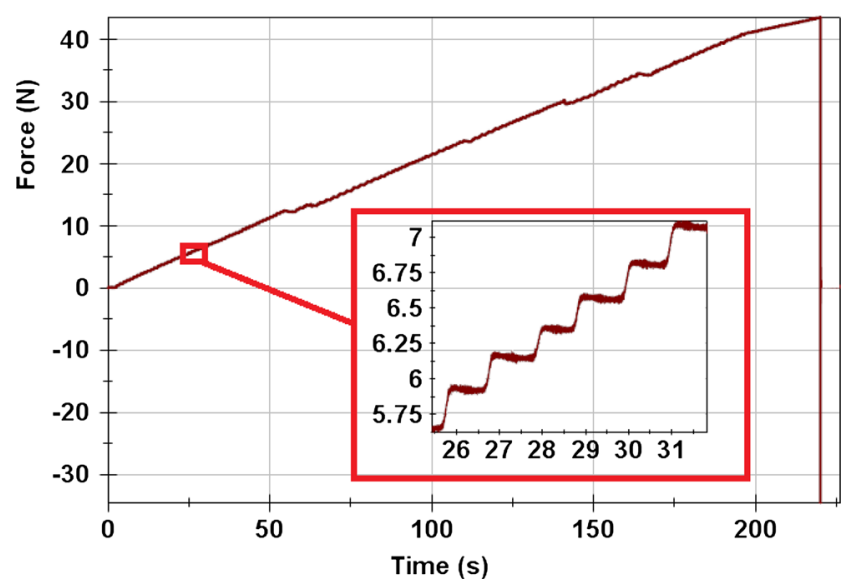

Fig. 17 Force applied to the cutting tool during deflection test 
A solid model of the micro end mill has also been created as shown in Fig. 18a, which is then imported into COMSOL Multiphysics finite element software to analyze the deflection of the micro end mill under the action of cutting forces. In the loading of the model, a fixed constraint has been applied to a portion of the shank, which is used for clamping to provide the same overhang used in experiments. A user-controlled mesh with tetrahedral elements was applied. This recorded force history is imported into COMSOL Multiphysics; cutting tool deflections are simulated and then com- pared to the experimental measurements as depicted in Fig. 17. It should be mentioned that the nominal measuring force of the probe is $0.1 \mathrm{~N}$, so it is quite negligible compared to the measured forces in this study.

\subsection{Finite element simulation-based analysis of tool deflection}

Once the finite element model is validated, it is possible to simulate the influence of worn tool forces on the tool deflec-
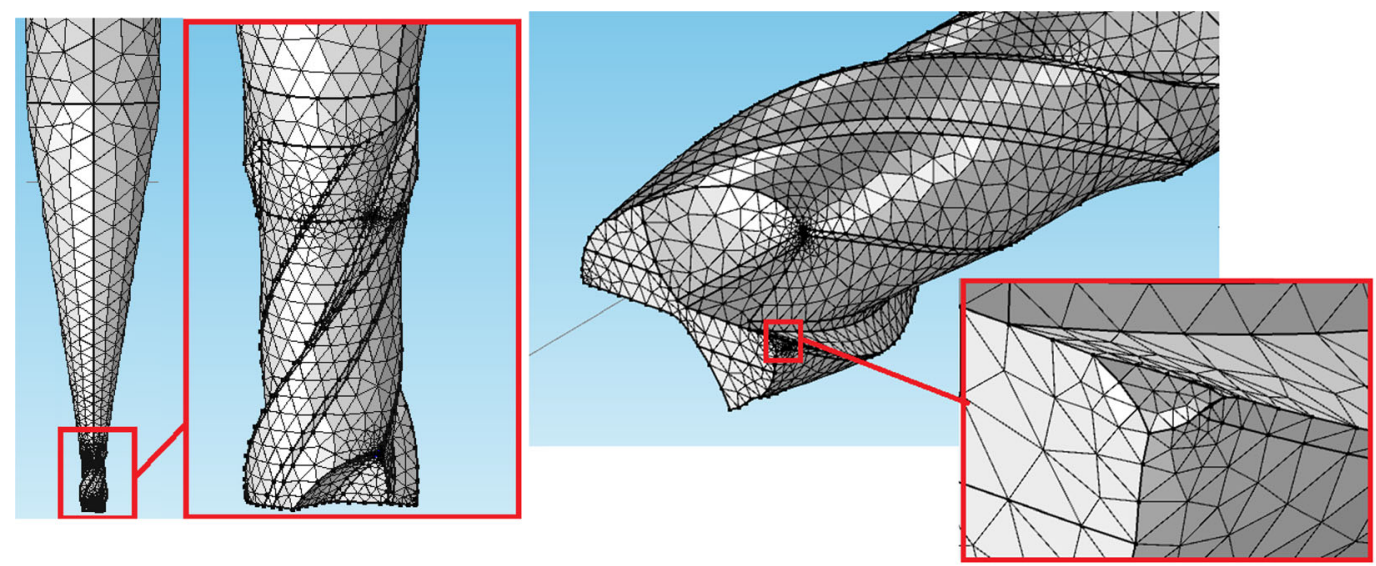

(a)
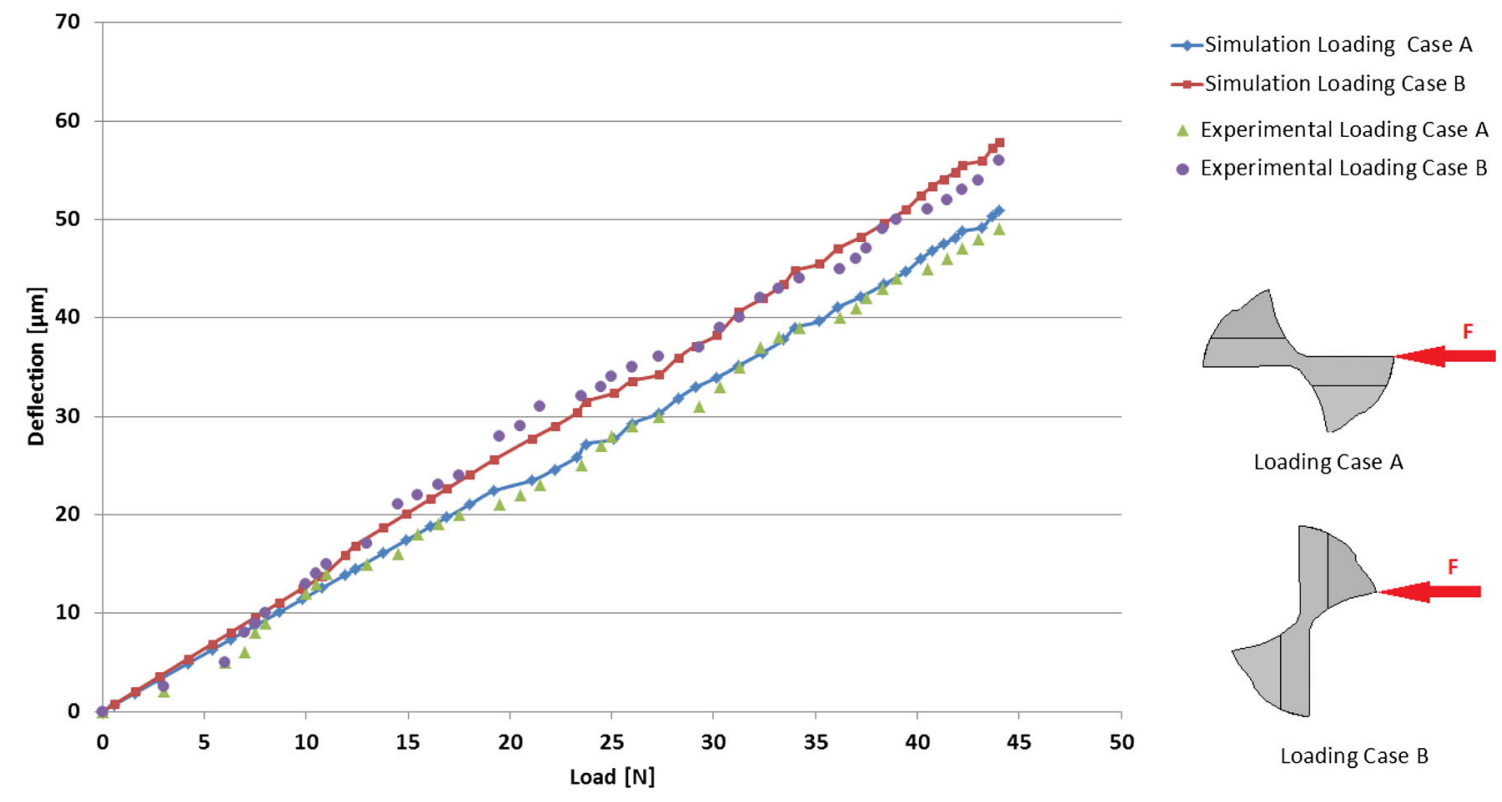

(b)

Fig. 18 a Finite element model of the end mill and $\mathbf{b}$ comparison between measured and simulated tool deflections 

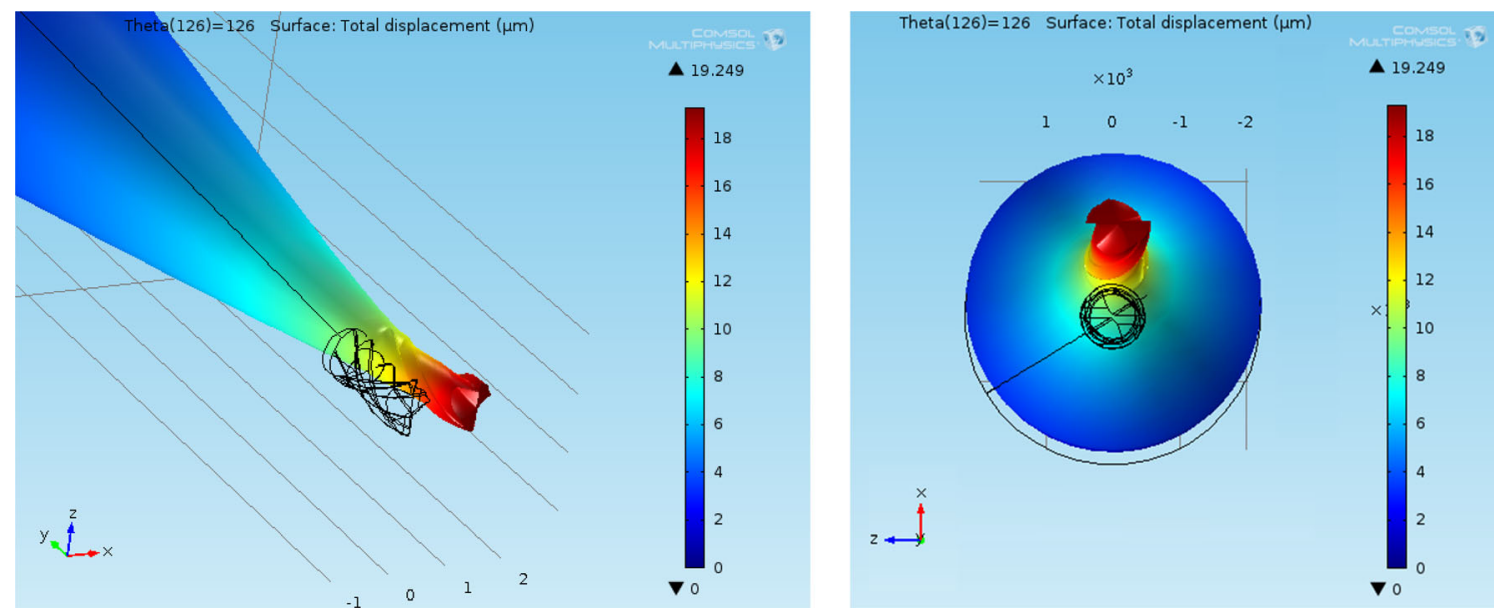

Fig. 19 Maximum deflection of the tool tip for end mill of experiment $\# 5$ at $\theta=126^{\circ}$
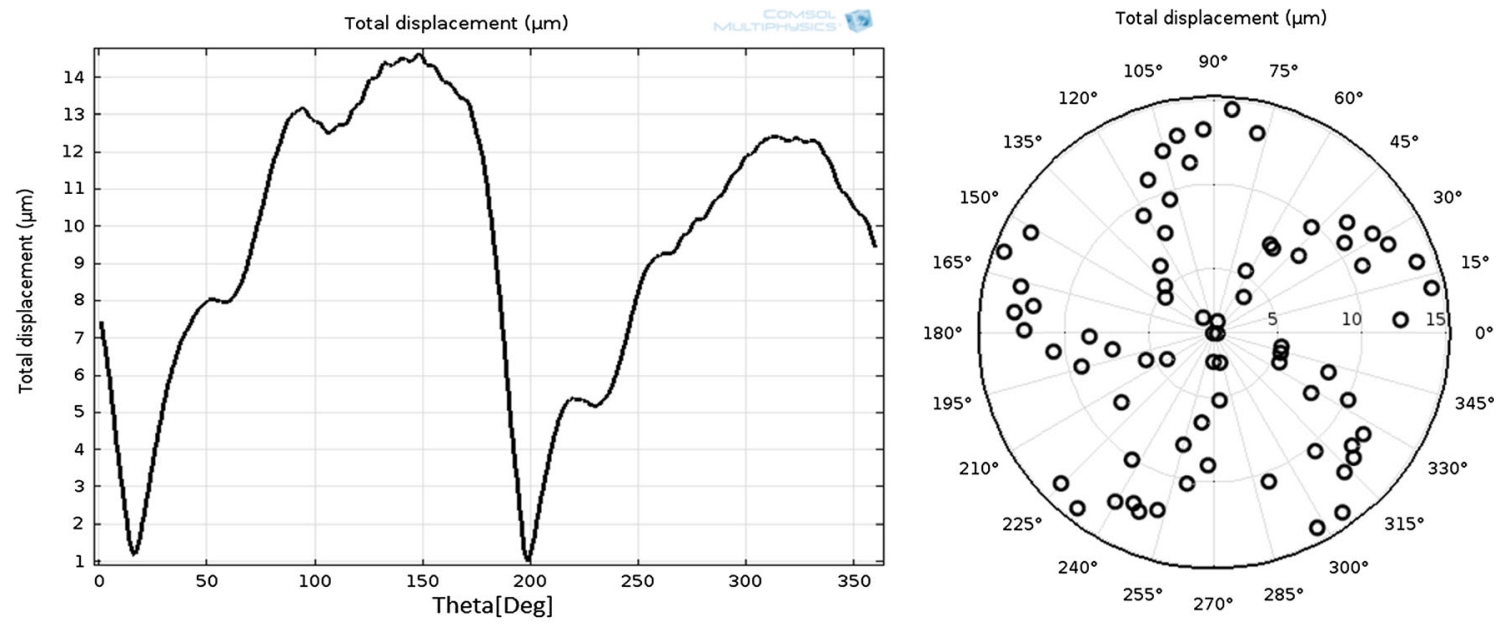

(a)
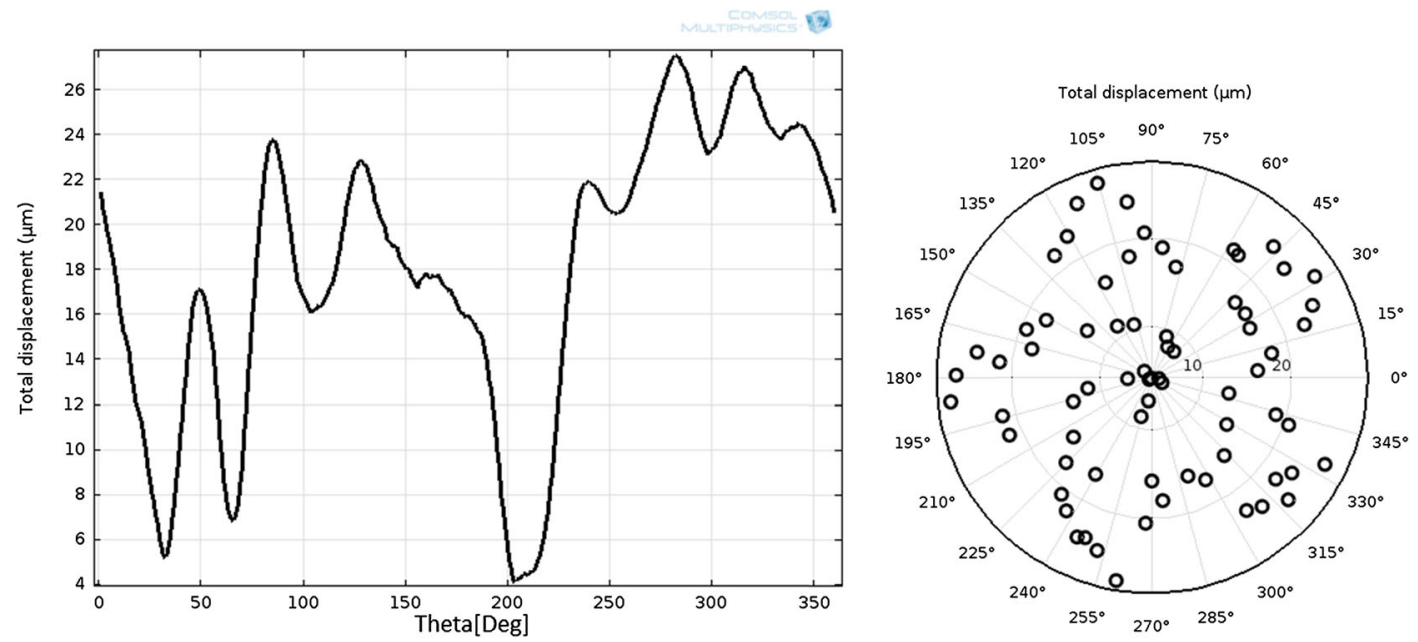

(b)

Fig. 20 Total displacements for (a) upsharp and (b) tool in experiment \#3 when machining with feed at $8 \mu \mathrm{m} /$ tooth 
tions. The radial and tangential components of the machining forces identified in the previous section are used in the simulation. In order to consider the influence of tool wear, the 3D wear zone images obtained in Fig. 2 are transferred to finite element models as shown in Fig. 18a and forces are distributed over the worn area. A static analysis has been performed using Solid Mechanics Module of COMSOL Multiphysics software, and one revolution of the cutting process is simulated and corresponding deflection of the end mill is obtained. Figure 19 illustrates the maximum deflection of the micro end mill used in experiment $\# 5$ corresponding to $126^{\circ}$. A deflection value around $20 \mu \mathrm{m}$ was calculated. Tool tip deflection as a function of tool rotation angle is depicted in Fig. 20 for upsharp and for the tool in experiment \#3. Simulated tool tip deflection in polar coordinates at various angles with $5^{\circ}$ increment is also represented in Fig. 20.

The results of finite element analysis show that tools with a higher amount of wear experience a larger amount of deflections, as expected. Based on the results given in Fig. 20, maximum tool deflections are ranging between 14 and $26 \mu \mathrm{m}$. The magnitude of deflections is in the same order of magnitude when compared with studies from the literature [10-12].
Fig. 21 a Trace left by the tool at the point of failure as measured on workpiece and $\mathbf{b}$ force

measurements at the instant of tool breakage

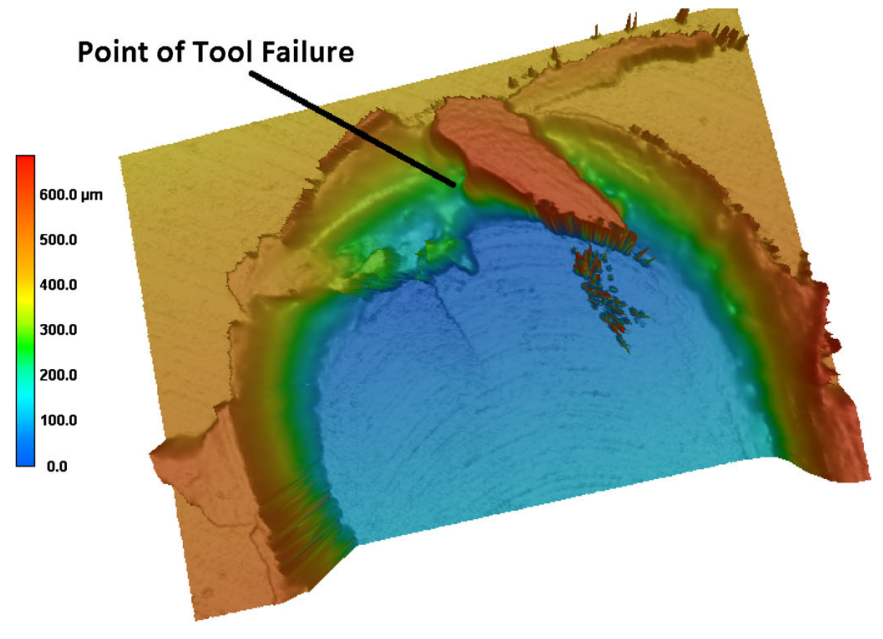

(a)

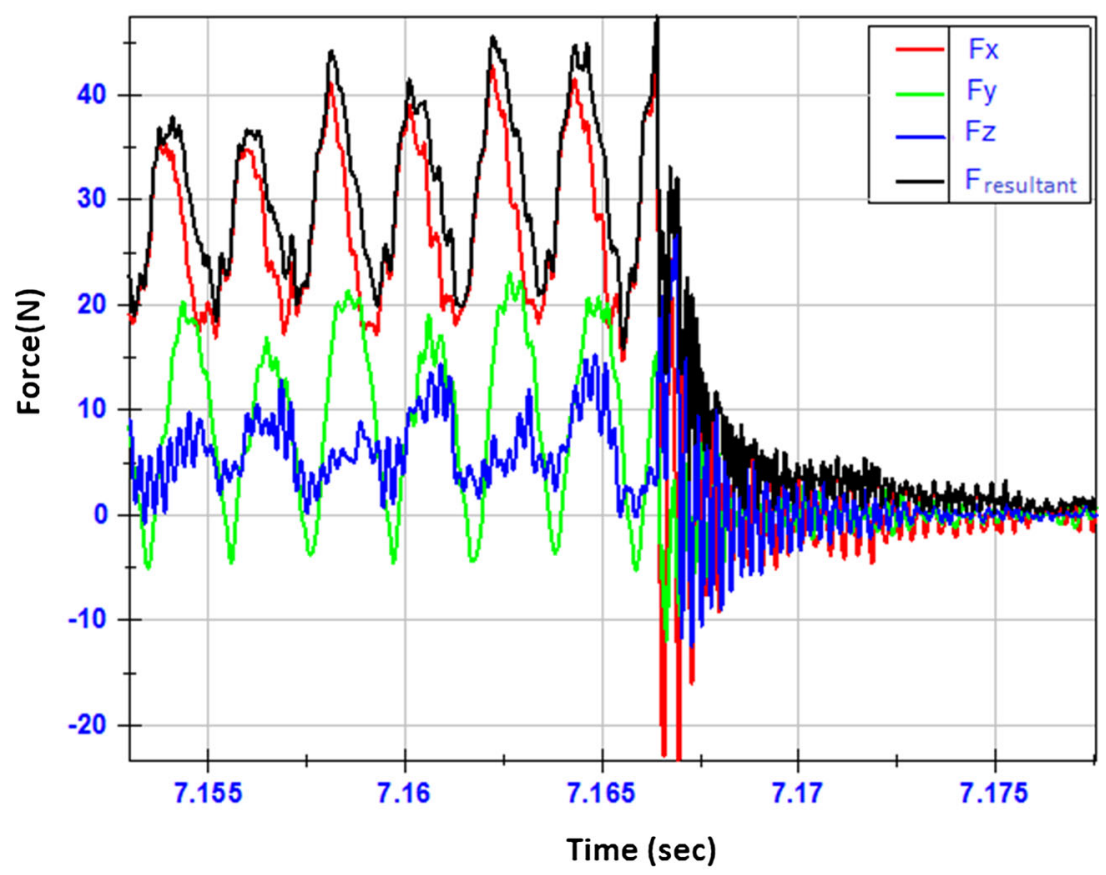

(b) 
In this study, the developed finite element model is used to predict tool failure using transverse rupture strength (TRS) as failure criterion. The worn tool of experimental test case \#10 was considered, and additional micro milling tests were performed with this tool until the tool fractures. The milling forces at the tool breakage were recorded. Figure 21a shows the 3D topography of the machined slot at the point of tool breakage. Figure $21 \mathrm{~b}$ depicts the force measurement at the instant of tool breakage. Investigation of the tool trace left on the workpiece at the end of the produced channel reveals that tool failure occurs at maximum tool deflection. The resultant force acting on the tool also agrees with the static tool deflection test results. The location of tool breakage agrees with the results shown in Fig. 20. Excessive burr formation around the channel also shows the influence of rounded cutting edges.

At this point, it is possible to investigate the condition of the micro cutting tool. The recorded forces are imported into the COMSOL software and the stresses on the tool body are calculated. Fang [27] reported traverse rupture strength of ultra-fine grain tungsten carbide as TRS $>3.7 \mathrm{GPa}$.
Figure 22a shows the results of finite element analysis for tool of experiment \#10 where the calculated maximum point of stress on the tool shank is shown. Figure $22 \mathrm{~b}$ shows the tip of the broken tool and its length. It can be seen that the finite element model predicts the tool failure point with a high accuracy. The deflection calculated in Fig. 22c also matches well with the deflection experiments given in Fig. 16.

\section{Conclusions}

The influence of tool wear on milling forces, surface roughness, and tool deflections has been studied using experimental, analytical, and computational techniques. The influence of milling conditions on the tool wear and the influence of tool wear on milling forces have been investigated. The tool wear and milling forces are used in finite element simulation model of the micro end mill as inputs to analyze the tool deflections and tool breakage. The developed model is shown to produce results matching the experimental observations. The results of this study can be stated as

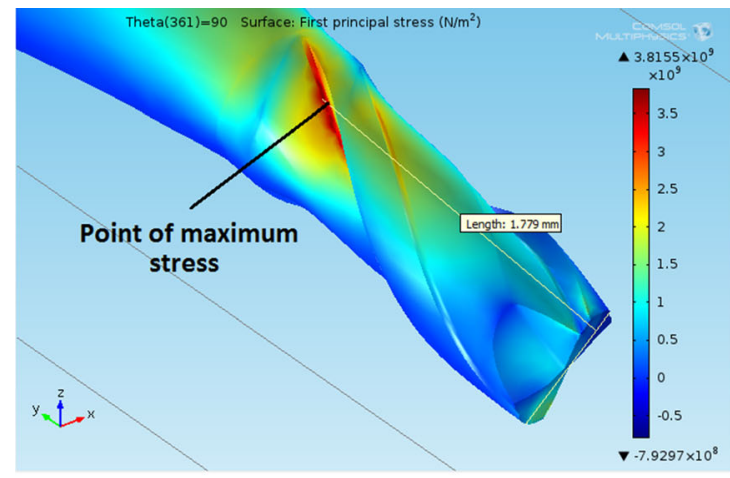

(a)

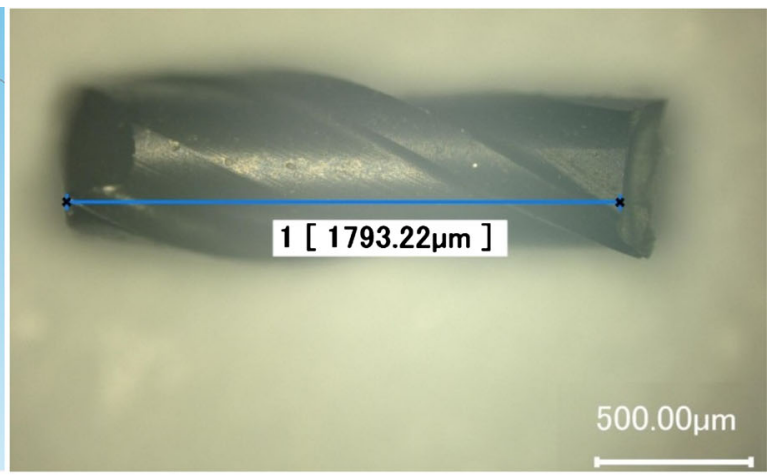

(b)

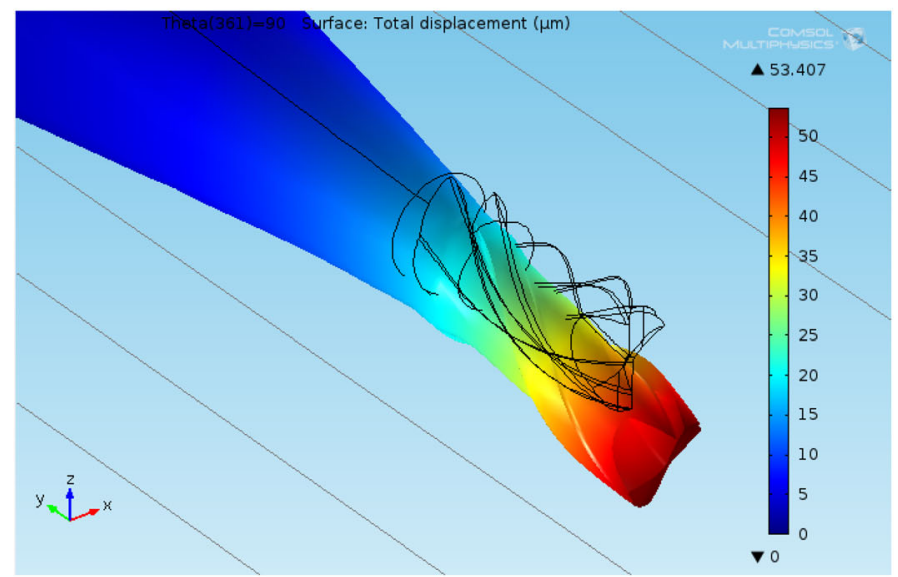

(c)

Fig. 22 a Maximum stresses on the micro tool, $\mathbf{b}$ measured length of broken micro end mill, and $\mathbf{c}$ maximum deflection of the micro tool 
- Radial immersion and feed per tooth values must be selected in conjunction during the process planning stage of pocket micro milling. In our experiments, $60 \%$ radial immersion yielded better tool performance compared to lower and higher radial immersion values.

- During circular pocket micro milling operation, tool wear is observed to evolve as edge rounding and flank wear increase. Relative tool diameter reduction, which is directly related to edge rounding of the tools, can be considered as a measure of tool wear, which is relatively easy to monitor during the micro milling process.

- A proper selection of feed per tooth and radial immersion leads to a balanced edge rounding and flank wear development. In this wear case, feed per tooth may be increased in order to be able to conduct machining effectively as tool wear progresses. It must be noted that this is limited by the allowable tool deflections.

- Predicting tool deflections and tool breakage during micro milling allows for development of tool condition monitoring based on the physics of the process. Tool breakage prediction with $0.8 \mathrm{~mm}$ diameter tungsten carbide micro end mill agrees well with the experimental results. However, tool breakage predictions for smaller diameter end mills, where the material effect becomes more pronounced, would require further study.

Acknowledgments The authors would like to acknowledge the Scientific and Technological Research Council of Turkey for the financial support of this project through project MAG110M660. The authors would also like to thank the Ministry of Development of Turkey (HAMIT-Micro System Design and Manufacturing Research Center). The authors also thank Dr. Șakir Baytaroğlu and Mr. Mustafa Kılıç for their help during the experiments.

\section{References}

1. Davim JP, Jackson MP (Ed.) (2009) Nano and micromachining. ISTE-Wiley, London ISBN: 978-1-84821-103-2

2. Chae J, Park SS, Freiheit T (2006) Investigation of micro-cutting operations. Int J Mach Tools Manuf 45(3-4):313-332

3. Li H, Lai X, Li C, Feng J, Ni J (2008) Modelling and experimental analysis of the effects of tool wear, minimum chip thickness and micro tool geometry on the surface roughness in micro-end-milling. J Micromech Microeng 18:025006

4. Aramcharoen A, Mativenga PT (2009) Size effect and tool geometry in micromilling of tool steel. Precis Eng 33:402-407

5. Karpat Y (2009) Investigation of the effect of cutting tool edge radius on material separation due to ductile fracture in machining. Int J Mech Sci 51(7):541-546

6. Vogler MP, Kapoor SG, DeVor RE (2004) On the modeling and analysis of machining performance in micro-end milling, part II: cutting force prediction. Trans ASME J Manuf Sci Eng 126(4): 695-705

7. Abdelrahman Elkaseer AM, Dimov SS, Popov KB, Minev RM (2014) Tool wear in micro-end milling: material microstructure effects, modeling, and experimental validation. J Micro Nano Manuf 2
8. Li C, Lai X, Li H, Ni J (2007) Modeling of three-dimensional cutting forces in micro-end-milling. J Micromech Micro Eng 17: 671-678

9. Uriarte L, Herrero A, Zatarain M, Santiso G, Lopéz de Lacalle LN, Lamikiz A, Albizuri J (2007) Error budget and stiffness chain assessment in a micromilling machine equipped with tools less than $0.3 \mathrm{~mm}$ in diameter. Precis Eng 31(2007):1-12

10. Mamedov A, Layegh SE, Lazoglu I (2015) Instantaneous tool deflection model for micro milling. Int $\mathrm{J}$ Adv Manuf Technol. doi:10.1007/s00170-015-6877-9

11. Rodrigues P, Labarga JE (2014) Tool deflection model for micromilling process. Int J Adv Manuf Technol 76:199-207. doi: 10.1007/s00170-014-5890-8

12. Mijušković G, Krajnik P, Kopač J (2015) Analysis of tool deflection in micro milling of graphite electrodes. Int J Adv Manuf Technol 76:209-217. doi:10.1007/s00170-013-5536-2

13. Bao WY, Tansel IN (2000) Modeling micro-end-milling operations. Part III: influence of tool wear. Int J Mach Tools Manuf 40(15): 2193-2211

14. Camara MA, Campos Rubio JC, Abrao AM, Davim JP (2012) State of the art on micromilling of materials, a review. J Mater Sci Technol 28(8):673-685

15. Saedon JB, Soo SL, Aspinwall DK, Barnacle A, Saad NH (2012) Prediction and optimization of tool life in micromilling AISI D2 ( 62 HRC) hardened steel International Symposium on Robotics and Intelligent Sensors 2012 (IRIS). Proc Eng 41:1674-1683

16. Thepsonthi T, Özel T (2014) An integrated toolpath and process parameter optimization for high-performance micro-milling process of Ti-6Al-4V titanium alloy. Int J Adv Manuf Technol 75:57-75. doi:10.1007/s00170-014-6102-2

17. Cardoso P, Davim JP (2010) Optimization of surface roughness in micromilling. Mater Manuf Process 25(10):1115-1119

18. Oliaei SNB, Karpat Y (2014) Experimental investigations on micro milling of Stavax stainless steel, Procedia CIRP 14: 377-382 (6th CIRP International Conference on High Performance Cutting, HPC2014)

19. Liu H, Sun Y, Geng Y, Shan D (2015) Experimental research of milling force and surface quality for TC4 titanium alloy of micro-milling. Int J Adv Manuf Technol 79:705-716. doi:10. 1007/s00170-015-6844-5

20. Jun M, Devor RE, Kapoor SG, Englert F (2008) Experimental investigation of machinability and tool wear in micro-end milling. Trans NAMRI/SME 36:201-208

21. Arizmendi M, Campa FJ, Fernandez J, de LLN L, Gil A, Bilbao E, Veiga F, Lamikiz A (2009) Model for surface topography prediction in peripheral milling considering tool vibration. CIRP Ann Manuf Technol 58:93-96

22. Arizmendi M, Fernandez J, Lopez de Lacalle LN, Lamikiz A, Gil A, Sanchez JA, Campa FJ, Veiga F (2008) Model development for the prediction of surface topography generated by ball-end mills taking into account the tool parallel axis offset. CIRP Ann Manuf Technol 57:101-104

23. Leach R (2013) Characterisation of areal surface texture. Springer, Berlin

24. Altintas Y (2012) Manufacturing automation, metal cutting mechanics, machine tool vibrations and CNC design, 2nd edn. Cambridge University Press, Cambridge

25. Zhou L, Peng FY, Yana R, Yao PF, Yang CC, Li B (2015) Analytical modeling and experimental validation of micro endmilling cutting forces considering edge radius and material strengthening effects. Int J Mach Tools Manuf 97:29-41

26. Salgado MA, Lopez de Lacalle LN, Lamikiz A, Munoa J, Sanchez JA (2005) Evaluation of the stiffness chain on the deflection of endmills under cutting forces. Int J Mach Tools Manuf 45:727-739

27. Fang ZZ (2005) Correlation of transverse rupture strength of WCCo with hardness. Int J Refract Met Hard Mater 23(2):119-127 